\title{
Thermal techniques for reshaping the cornea
}

\section{B. Stuart Trembly}

B. Stuart Trembly, "Thermal techniques for reshaping the cornea," Proc. SPIE 10297, Matching the Energy Source to the Clinical Need: A Critical Review, 1029704 (24 January 2000); doi: 10.1117/12.375224

SPIE. Event: Digital Optical Computing, 1990, Los Angeles, United States 


\title{
Thermal Techniques for Reshaping the Cornea
}

\author{
B. Stuart Trembly \\ Thayer School of Engineering, Dartmouth College, Hanover, New \\ Hampshire $03755^{\mathrm{a}}$
}

\begin{abstract}
The shape of the cornea of the eye can be modified to correct permanently for nearsightedness or far-sightedness. Heat energy can be delivered to the cornea for this purpose in order to elevate the collagen in mid-cornea to its shrinkage temperature of about $60^{\circ} \mathrm{C}$. When a suitable pattern of shrinkage is created in the peripheral cornea, the central cornea may steepen or flatten in response, and this change in curvature may serve as a refractive correction. This paper reviews the following methods for heating the cornea for this purpose: conduction, radio-frequency, laser, and microwave.
\end{abstract}

Keywords: refraction, cornea, thermokeratoplasty, radio frequency, laser, microwave

\section{THERMOKERATOPLASTY}

\section{Correction of Refraction}

New methods for correction of near-sightedness (myopia), far-sightedness (hyperopia), and astigmatism are of great interest to biomedical researchers. In the U.S., roughly half of the population requires some correction to vision. Many seek a permanent correction in order to avoid the use of spectacles or contact lenses. Current methods for permanent correction include two laser surgery procedures called photorefractive keratectomy (PRK) and laser in-situ keratomileusis (LASIK). PRK uses an excimer laser to ablate portions of the outermost layer of the eye- the cornea- of a myope through a photochemical reaction, as opposed to a thermal effect. This flattens the cornea to correct near-sightedness, as will be reviewed below. LASIK is a similar procedure, except that the cornea first is sliced at mid-depth to form a hinged flap. The excimer laser ablates the exposed cornea to flatten it, then the flap is replaced. This method spares the outermost layer of cells on the cornea, the epithelium, which is removed in the PRK procedure, and thus avoids the healing period when the epithelium regrows (Fig. 1).

Researchers have investigated alternatives to PRK and LASIK. Features of an improved method would be: sparing of the epithelium, elimination of surgery, elimination of any intervention in the central cornea, where the image passes, and avoidance of any thinning of the cornea, which weakens it. Some of the new techniques being investigated exploit thermal effects in the cornea to change refraction of the eye; some thermal techniques

\footnotetext{
${ }^{a}$ Correspondence: b.stuart.trembly@dartmouth.edy phone: (603)646-2118; fax; (603) 646-3856 Matching the Energy Source to the Cthical Need:A Critical Review, edited by Thomas P. Ryan, Proc. of SPIE Vol. 10297 (Vol. CR75), 1029704 - (c) (2000) 2017 SPIE CCC code: $0277-786 X / 17 / \$ 18 \cdot$ doi: $10.1117 / 12.375224$ 51

Proc. of SPIE Vol. 10297 1029704-1
} 
Ihetraditional technique Ihe IASKKtechnique

[PRK]
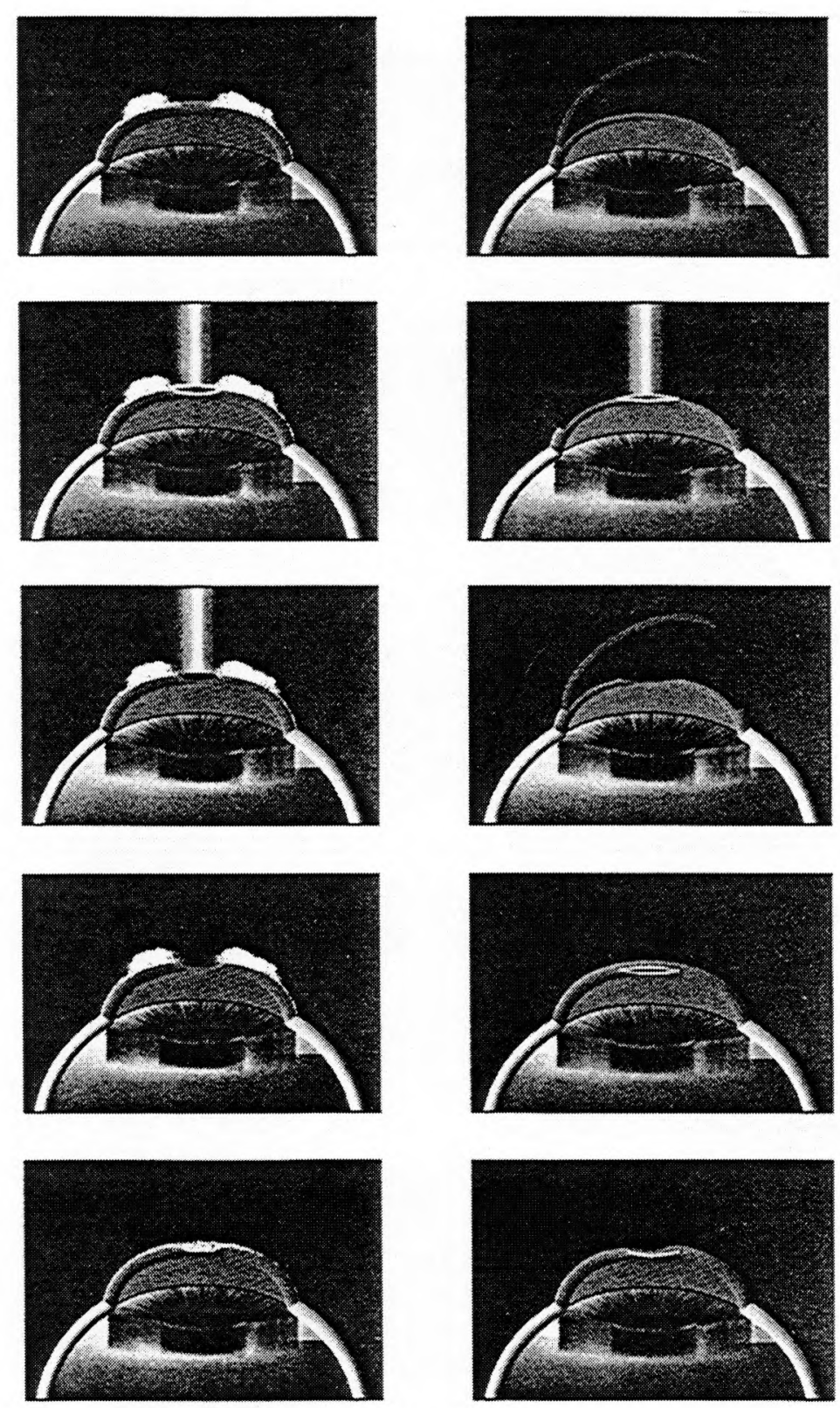

Fig. 1 [Laservue brochure] [32] 
Matching the Energy Source to the Clinical Need / 53

have some or all of the advantages listed. Thermal techniques will be described in this paper after the anatomy and function of the eye is reviewed.

\section{Anatomical Background}

The human eye is an optical system that bends rays incident from a source at infinity onto the retina for detection. The dioptric power of the eye is commonly expressed in diopters (D), which is simply the inverse of the focal length in air, expressed in meters ${ }^{1}$. Thus, someone with refraction of $42 \mathrm{D}$ has a focal length of $23.8 \mathrm{~mm}$. Most ray bending occurs at the cornea-air interface; the lens of the eye serves mainly to allow focussing on objects at varying distances. The cornea and lens in combination with the axial distance to the retina determines whether a person is emmetropic (normal vision), myopic, or hyperopic. Fig. 2 contrasts the myopic and hyperopic eye. The myopic eye has too much dioptric power, causing the image to be focussed in front of the retina; refraction will be corrected toward emmetropia if the cornea is flattened to reduce dioptric power. The cornea of the hyperopic eye must be steepened to correct refraction. Note it is the curvature of only the central portion of the cornea that is relevant, because this is where the image passes. This central portion is called the optical zone. The diameter of the optical zone varies with pupil diameter as the pupil responds to ambient light. Astigmatic vision is caused by variations in curvature around a circle projected onto the cornea surface. Keratoconus is a disease of the cornea characterized by a steep, conical projection of the cornea (Fig. 3); some of the thermal methods described in this paper were developed to treat keratoconus.

Many techniques for refractive surgery manipulate the cornea, because is accessible and has the greatest effect on refraction in the eye. Ren, et al. ${ }^{1}$ have reviewed the anatomy and function of the cornea; this is summarized below. The human cornea is $0.55 \mathrm{~mm}$ thick at the center and $0.7 \mathrm{~mm}$ thick at the periphery. It is shown in cross-section in Fig. 4, which identifies five layers: epithelium, Bowman's layer, stroma, Decemet's membrane, and endothelium. The epithelium is a cellular layer 0.03 to $0.05 \mathrm{~mm}$ thick and 5 to 8 cells thick. It serves as a barrier between the eye and the environment and as a suitable optical surface made smooth by the overlying tear film. It can regenerate after being damaged. Bowman's layer is an acellular layer of collagen fibrils that is $0.012 \mathrm{~mm}$ thick. It serves to maintain the shape of the cornea through its inelasticity, and it cannot regenerate. The stroma is about $0.5 \mathrm{~mm}$ thick. It consists of a regular, lamellar array of collagen fibers that make the cornea transparent by the regularity of the structure.

Keratocytes in the stroma can generate collagen as part of a wound-healing response if the stroma is damaged. Descemet's membrane is an acellular layer of thickness 0.010 to $0.012 \mathrm{~mm}$. The endothelium is a single layer of cells 0.04 to $0.06 \mathrm{~mm}$ thick. It maintains the correct corneal hydration by actively pumping water out of the cornea; this action maintains corneal transparency. These cells cannot regenerate in human adults. Any technique for modifying refraction must not damage the endothelium ${ }^{1}$. The cornea has transparent nerves, but no blood vessels; oxygen is supplied by the tear film.

\section{Shrinkage of Corneal Collagen}

The basis of thermokeratoplasty techniques is the shrinkage of corneal collagen, which has been observed to begin at a temperature between $55^{\circ} \mathrm{C}$ and $58^{\circ} \mathrm{C}^{2}$. Through a 


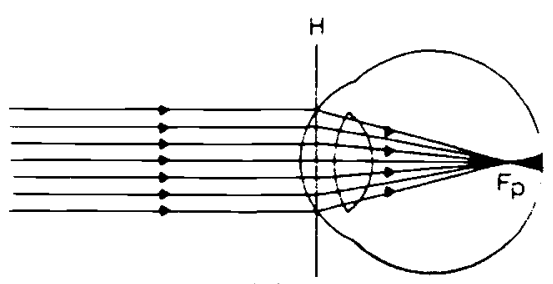

(a)

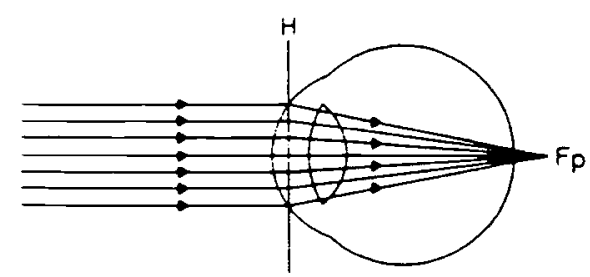

(b)

Fig, 2 Blurring of the image of a distant point due to myopia (a) and hyperopia (b). $\mathrm{H}$ is the principal plane, and $F_{p}$ is the posterior principal focus. (From Davson, Physiology of the Eye) [33]

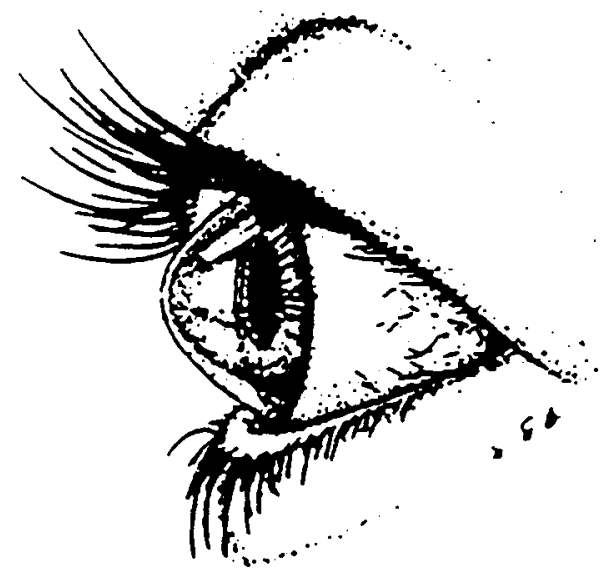

Fig. 3 Keratoconus. (From Dorland, Illustrated Medical Dictionary) [34] 


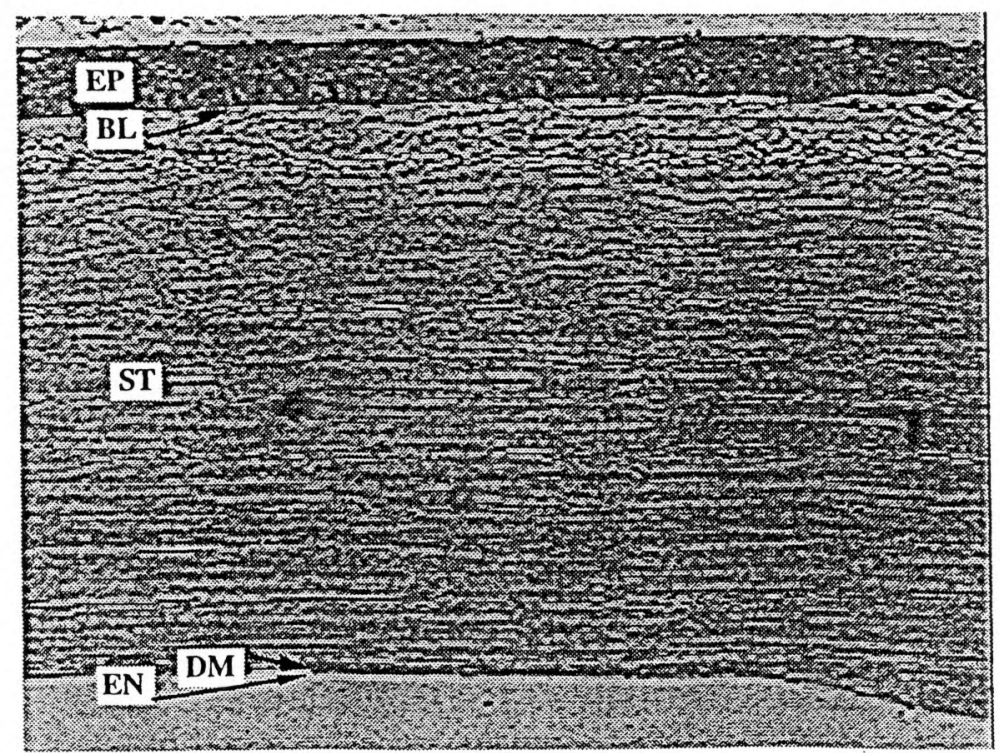

Fig. 4 Histologic section of a human cornea stained with hematoxylin-eosin reveals the outer epithelium (EP), acellular Bowman's layer (BL), stroma (ST), Descemet's membrane (DM), and endothelial monolayer (EN) (100x mag.) [36]

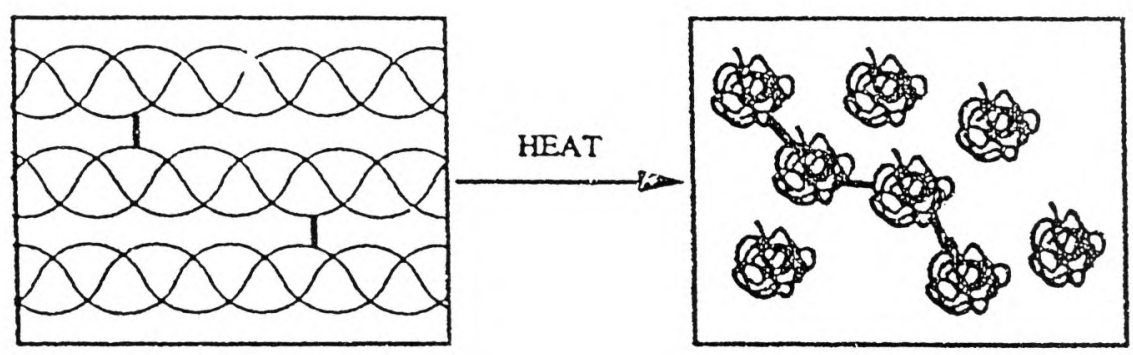

Fig. 5 Mechanism of collagen shrinkage effect: (a) Triple helical collagen elements are cross-linked to form a collagen fiber. (b) When heat is applied, interpeptide hydrogen bonds break, resulting in the collapse of the triple helix. Intertropocollagen crosslinks remain intact. [Ren, et a1., 1995] [1] 
suitable choice of shrinkage pattern on the cornea, the curvature of the optical zone may be steepened or flattened by exploiting the shrinkage of collagen in the cornea. A later study found that shrinkage began at $60^{\circ} \mathrm{C}$, attained a maximum effect of $57 \pm 12 \%$ shrinkage between 75 and $80^{\circ} \mathrm{C}$, and weakened in effect above $100^{\circ} \mathrm{C}^{3}$. The mechanism of shrinkage has been described as follows: "the interpeptide hydrogen bonds between the procollagen fibers collapse. This collapse causes the procollagen to fold back on itself, pulling the tropocollagen fibers closer together and shortening the length of the collagen fiber."' See Fig. 5. When shrinkage temperature is attained, varying degrees of opacity appear immediately in the cornea at the heating site; opacity tends to clear in the weeks and months after treatment.

\section{Conduction Heating of the Cornea}

The simplest method for delivering heat energy to the cornea is to bring a hot object into contact with it thus transferring energy into the cornea by conduction. This method was used by Lans ${ }^{4}$, who is considered the first to describe a thermokeratoplasty procedure.

Gasset and Kaufman ${ }^{5}$ used a conduction probe heated to $90^{\circ} \mathrm{C}$ or $130^{\circ} \mathrm{C}$ to treat 59 eyes of keratokonus patients (Fig. 6). The temperature response measured in the epithelium and endothelium with this device are shown in Fig. 8 from Shaw and Gassett ${ }^{6}$. The probe was applied lightly with a rotary motion around the apex of the cone with continuous irrigation. Flattening of the cornea was "almost instantaneous". The epithelium regrew in 4 to 6 days, and a "transitory" period of corneal haze was observed. After the two year follow-up period, flattening by an average of $10 \mathrm{D}$ was measured, and almost all patients had visual acuity of $20 / 30$ or better. The authors noted that further study would be necessary to standardize the treatment.

Keates and Dingle ${ }^{7}$ used a conduction probe heated to $120^{\circ} \mathrm{C}$ to flatten the corneas of 9 keratoconus patients. Between 4 and 9 instantaneous applications were made by the surgeon. Re-epithelialization occurred in 5 to 7 days, and corneal haze at the treatment site was present for 1 to 3 months. The authors stated, "Our patients demonstrated a prompt return of corneal curvature to pretreatment measurements despite profound flattening at the time of thermokeratoplasty." They noted that they had treated more severe cases of keratoconus than did Gasset and Kaufman ${ }^{5}$, and this factor may explain their striking lack of success.

Fyodorov, inventor of the surgical radial keratotomy technique for myopia, developed a thermal conduction technique, designated radial thermokeratoplasty (rTKP), to correct hyperopia. The method was evaluated by Neumann, et al. ${ }^{8}$, who treated 24 eye bank eyes with this method. A thin cautery probe was inserted to $95 \%$ depth in the cornea after pachymetry readings were made of local corneal thickness. The diameter of the probe was not stated, but histological photos in Feldman, et al. ${ }^{9}$ suggest is was roughly $0.2 \mathrm{~mm}$. The probe was heated to $600^{\circ} \mathrm{C}$ for a time that was not specified. (The time period was stated by Feldman, et al. ${ }^{9}$ to be $0.3 \mathrm{sec}$ in a study that also used Fyodorov's technique.) Multiple heatings were performed to form several treatment patterns, in which heated spots formed radial lines outward from the optical zone; the number of radial lines, the number of spots per line, and the diameter of the optical zone were varied. Keratometer measurements before and after treatment showed central steepening of the cornea by 16 to 19 diopters, depending upon the treatment pattern. Steepening was greater with a 


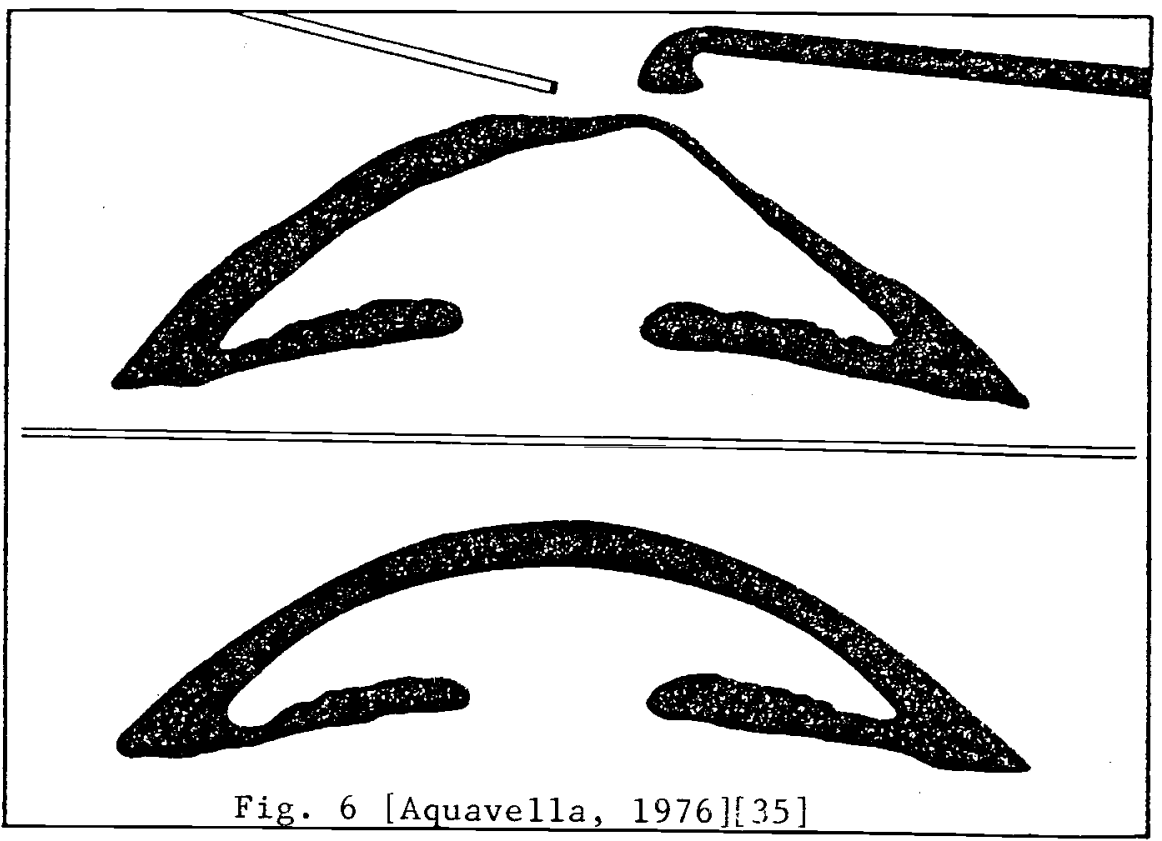

Schematic drawing of probe application. Upper figure: probe being applied to apex of cone. Note irrigator tip. Lower figure: depicts the ideal corneal curvature situation. Probe applications are designed to achieve this result.

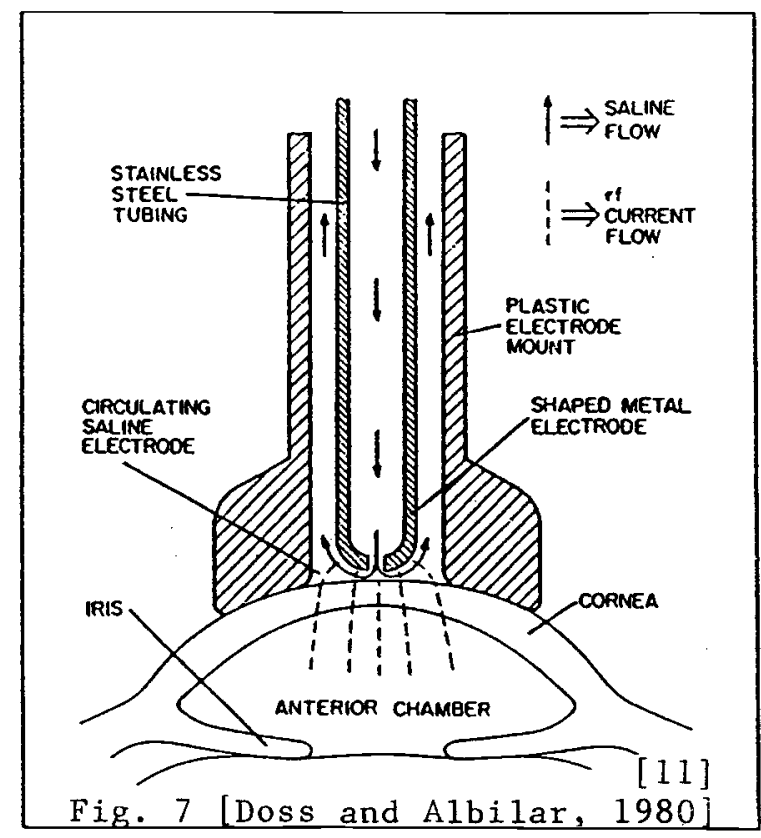

Circulating Salinc Electrode (CSE). Electric currents flow through the cornca. generating heat. Epithelium is cooled by the flow of saline through the $0.5 \mathrm{~mm}$ gap beiween the metallic electrode and the cornea. 
58 / Critical Reviews Vol. CR75
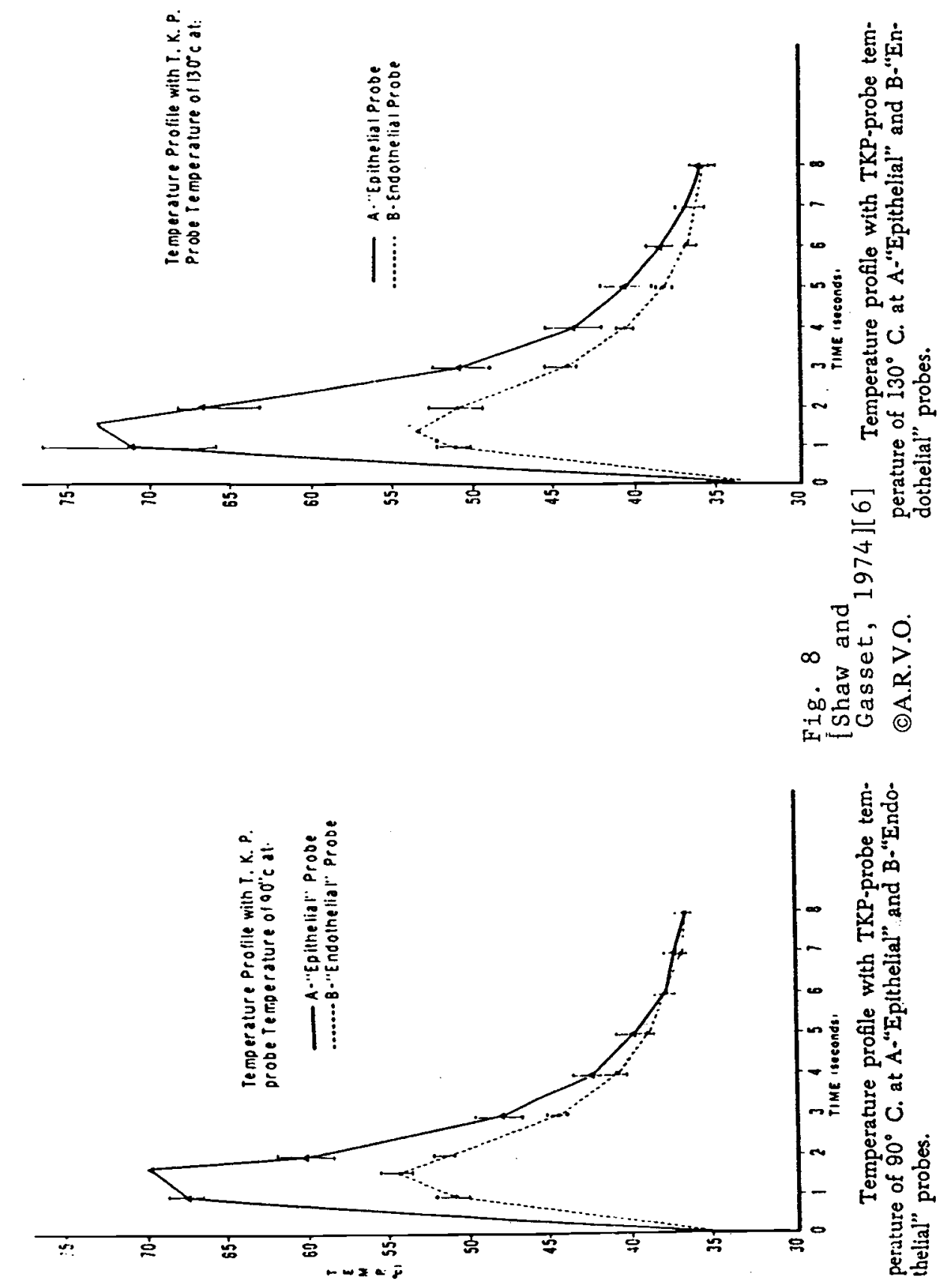

Proc. of SPIE Vol. 10297 1029704-8 
Matching the Energy Source to the Clinical Need / 59

greater number of radial lines and with a decrease in the diameter of the optical zone, i.e., the central circle excluded from treatment.

Neumann, et al. ${ }^{10}$ treated 61 hyperopic patients using the technique described above and followed them for a year. The diameter of the untreated optical zone was set to three ranges: 5.0 to $6.75 \mathrm{~mm}, 7.0$ to $7.75 \mathrm{~mm}$, and $8.0 \mathrm{~mm}$ and over. Immediately after treatment, the authors observed "white annular areas of coagulated protein and reactive stromal edema around each focal burn. Between each ray of heat application, annular stress lines form in the stroma as the collagen contracts and flattens. This peripheral flattening causes the central optical zone to steepen, forming folds in Descemet's membrane." Although the heating probe penetrated $95 \%$ of the cornea, they observed that the scar extended only to $70-80 \%$ depth, due to the accumulated effect of heat energy lost from the probe along its length.

One day after surgery, the degree of steepening was $7.8 \mathrm{D}, 4.8 \mathrm{D}$, and $2.6 \mathrm{D}$, respectively, for the three successively larger untreated zones defined above. At five or six months, significant regression had occurred, and 54 to $73 \%$ of the steepening effect had been lost, depending upon the diameter of the untreated zone. At one year after treatment, an average of $68 \%$ of the refractive correction had regressed. No significant endothelial cell loss was observed.

Feldman, et al. ${ }^{9}$ evaluated the radial thermokeratoplasty technique through a study in eight rabbit eyes, which were followed for 30 days. Histological specimens were evaluated with light microscopy and transmission electron microscopy. Fig. 9 shows stromal coagulation in the probe track 2 days after treatment. Fig. 10 shows thinning of the stroma and deep re-epithelialization after one month. The authors observed endothelial damage at a radius of $0.3 \mathrm{~mm}$ from the center of the probe track, and they estimated that 5 to $14 \%$ of the endothelium could be damaged in a typical treatment. They concluded that safety of rTKP must be evaluated further before clinical trials.

\section{Radio Frequency Heating of the Cornea}

Radio frequency heating of tissue involves the flow of electrical current between two conductors in contact with the tissue. The movement of charge through tissue causes local absorption of heat energy at a rate proportional to the tissue resistivity and the square of the electrical current (ohmic heating). Significant heat absorption can occur below the tissue surface, because some current flowing between conductors placed at the surface will follow a fringing path away from the surface. In this way, an effect similar to the penetrating rTKP probes can be attained without surgical incisions into tissue. This electrical phenomenon depends on the geometry of the electrodes and not a penetration depth that depends on the frequency of the sinusoidal current.

Doss and Albilar ${ }^{11}$ designed an applicator to be placed on the surface of the cornea that heated according to these principles. A surface cooling system was incorporated to reduce the elevation of temperature at the cornea surface that would otherwise occur (Fig. 7). This novel system was capable of producing a maximum temperature at midcornea, instead of at the surface, even though no physical penetration was made. One advantage of this could be preservation of the epithelium, so that the patient would be spared the 


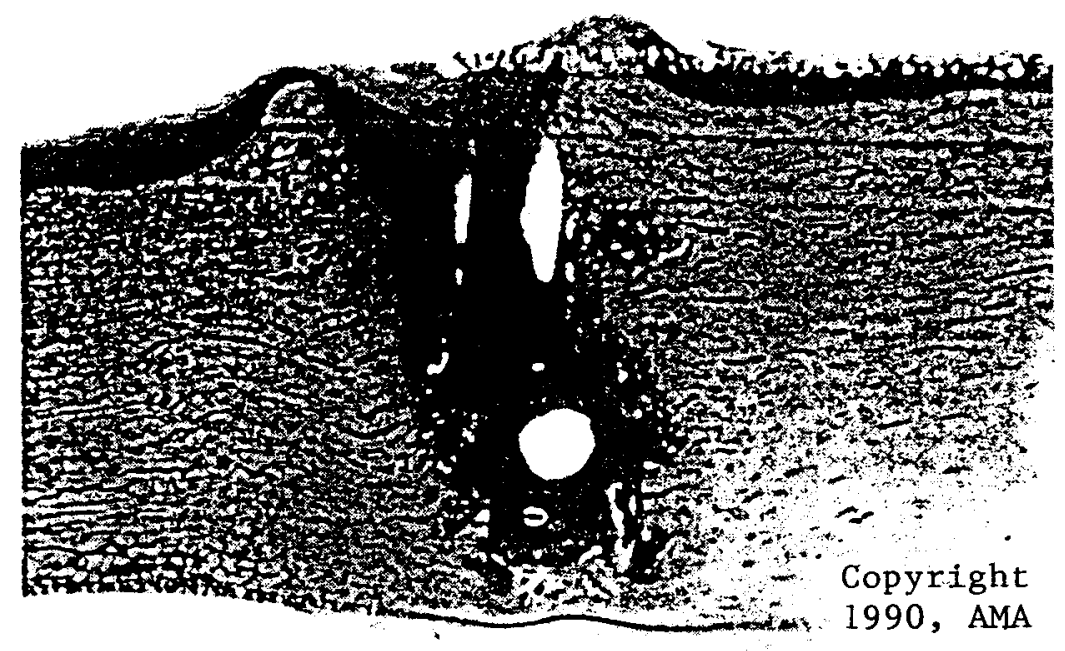

Light micrograph of the coagulation site disclosed epithelial healing, irregular margins, and thinning of Descemet's membrane underneath the coagulation and large retrocorneal membrane (four to five cell layers thick) (original magnification $\times 40$ ).

Fig. 9 [Feldman, et a1., 1990][9]

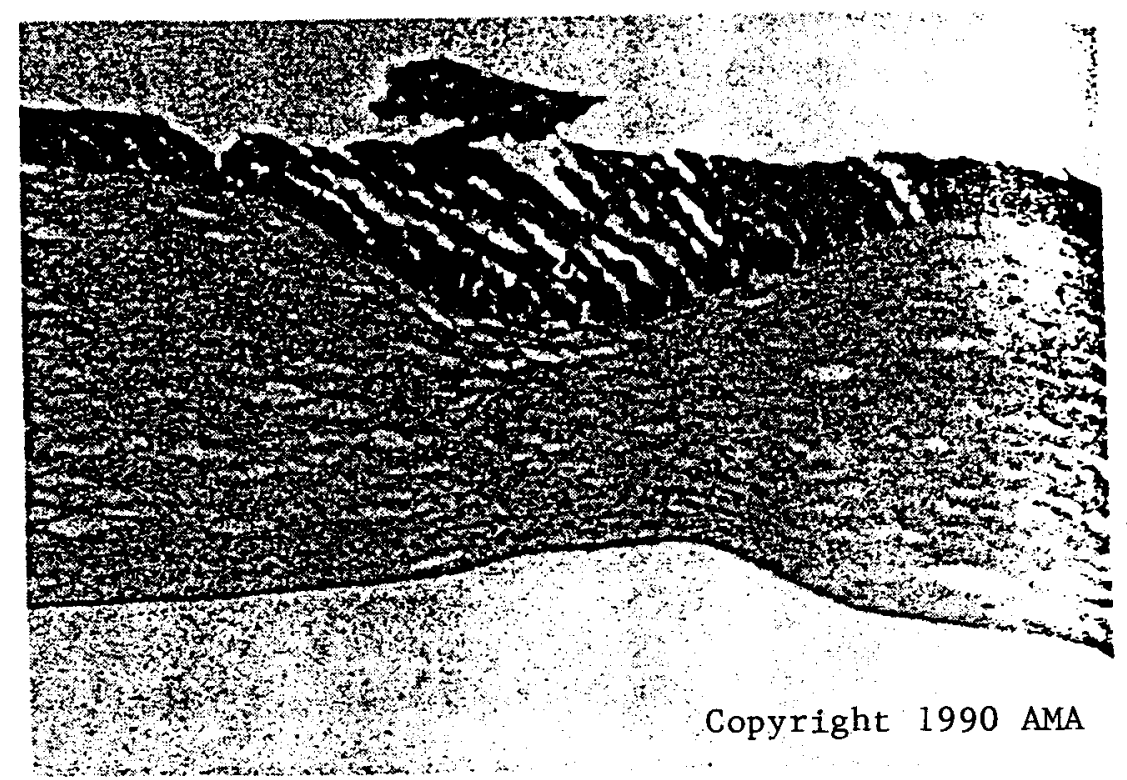

Light micrograph of a cornea 1 month following radial thermokeratoplasty. The cornea is thinned, the stroma is repopulated with keratocytes, and the retrocorneal membrane is two cell layers thick (original magnification $\times 40$ ). Fig. 10 [Feldman, et a1., 1990][9] 
regrowth period of 3 to 7 days. This applicator was designated the circulating saline electrode (CSE).

The CSE was used to heat pig corneas of thickness 0.6 to $0.9 \mathrm{~mm}$. The probe was driven at $1.6 \mathrm{MHz}$ and was cooled by isotonic saline at $37^{\circ} \mathrm{C}$ flowing at $40 \mathrm{ml} / \mathrm{min}$.

Thermocouples of diameter 25 or 50 micron were placed at various depths within the corneas. Heating duration was 4 seconds with a driving voltage of $40 \mathrm{Vrms}$, but the power was not specified. For comparison, heating was also performed for 2 seconds by a copper probe of $3 \mathrm{~mm}$ diameter pre-heated to $90^{\circ} \mathrm{C}$ and placed in contact with the corneal surface. The axial temperature distributions in the cornea are shown in Fig. 11. These results contrast the characteristic shallow temperature distribution of the surface conduction technique with the local temperature maximum at midcornea produced by the CSE technique.

Rowsey and Doss ${ }^{12}$ used the CSE to treat 5 keratoconus patients. The ring of the CSE inner electrode was specified as $2 \mathrm{~mm}$ in diameter; other parameters were as given above. The CSE produced flattening of the cornea by 4 to $57 \mathrm{D}$. Persistent corneal scars at the site of treatment were noted. As a practical matter, it was found that "Inadequate therapy occurs if the saline electrode is not placed in water-tight apposition to the corneal surface." Of the 5 patients, 2 were able to return to contact lens use and avoid the need for penetrating keratoplasty (i.e., surgery) to treat their keratoconus. The two who underwent penetrating keratoplasty had scanning electron microscopy that showed no endothelial damage beneath the CSE treatment site.

Rowsey ${ }^{13}$ reported that 10 to $30 \mathrm{D}$ of flattening was observed in 22 keratoconus patients heated by the CSE. However, significant problems were noted, and he stated, "The large standard deviation of results, consequent lack of predictability, corneal scar formation, and variable regression have caused us to discontinue this treatment modality in the treatment of keratoconus." The undesirable variablility and regression of effect on keratokonus had been noted by Keates and Dingle ${ }^{7}$, who treated keratoconus with a conduction probe; they speculated that severe cases of keratoconus should be excluded from a study in order to have the favorable results reported by Gasset and Kaufman ${ }^{5}$. It is possible that inclusion of severe keratoconus patients in the rTKP study by Rowsey contributed to the undesirable outcomes observed. Flattening of the central cornea is a treatment for myopia, but there have been no publications on this use of the CSE.

\section{Laser Interaction with the Cornea}

The absorption coefficient in tissue of laser energy of wavelength greater than about 1.4 microns is large enough to cause significant deposition of thermal energy in the cornea. Photon energy in this range is less than the energy of molecular bonds, and energy is absorbed as heat, especially by water ${ }^{14}$. This process differs from the photoablation process, in which molecular bonds are broken by the energy of an excimer laser (photorefractive keratectomy, PRK). A plot of absorption coefficient as a function of laser wavelength is given in Fig. 12. Notable points on the graph for corneal tissue are at 10.6 micron (CO2 laser), where the absorption coefficient is $90 \mathrm{~mm}^{-1}$ (penetration depth $=0.01 \mathrm{~mm}$ ) and at 2.1 micron (holmium:YAG laser), where the absorption coefficient is $2.5 \mathrm{~mm}^{-1}$ (penetration depth $=0.4 \mathrm{~mm}$ ). Also notable is the steep section of the plot 

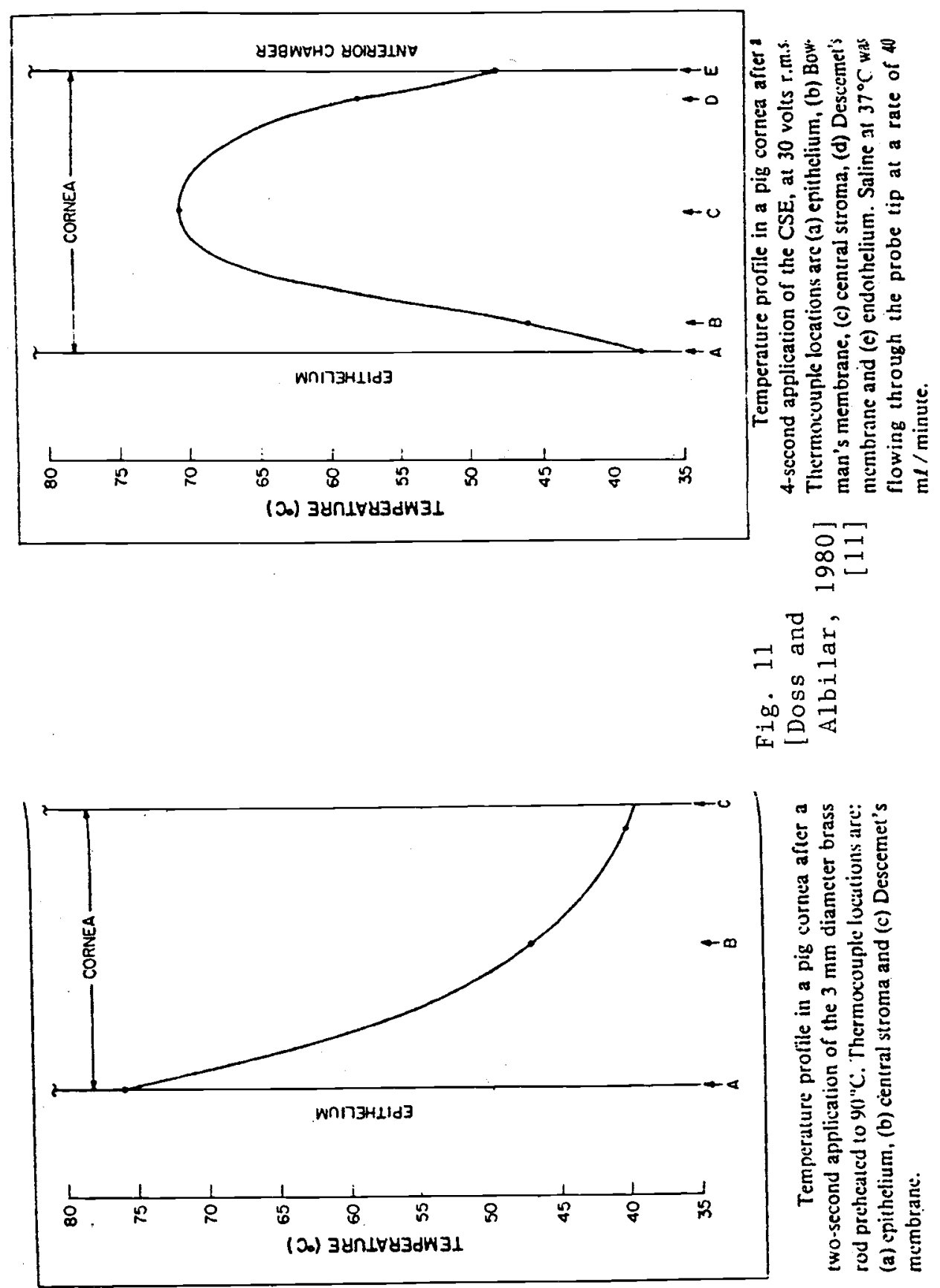
around 1.86 micron, where the tunability of the diode laser can be exploited to control penetration depth.

\section{Early Laser Thermokeratoplasty}

Peyman, et al. ${ }^{15}$ and Beckman, et al ${ }^{16}$ attempted to use the $\mathrm{CO} 2$ laser (wavelength $=10.6$ micron) to modify the shape of the cornea. They were not successful, possibly due to the superficial penetration of about $0.01 \mathrm{~mm}$ into the cornea of thickness $0.55 \mathrm{~mm}$; it is believed that shrinkage must be induced at depth in the stroma to effect stable changes in refraction ${ }^{17}$. Later groups applied lasers with shorter wavelengths and deeper penetration with greater success. Seiler, et al. ${ }^{18}$ used a holmium:YAG laser, and Horn, et al. ${ }^{19}$ used a cobalt:magnesium flouride laser with wavelength tunable between 1.65 to 2.25 micron. A tunable laser based on diode technology will be described in Sec. 11; the holimium:YAG laser will be described immediately below.

\section{Holmium:YAG Laser Thermokeratoplasty}

Moreira, et al.$^{20}$ heated the corneas of rabbits and eye bank eyes with a holmium:YAG laser that created heated spots forming circles of diameter 3 to $7 \mathrm{~mm}$. They observed an increase in central curvature of the cornea, and showed that the degree of increase was controlled by the diameter of the treatment circle; they supported this through rough agreement with a numerical model of the solid mechanics of the cornea.

The holmium:YAG laser has a wavelength of 2.1 microns, and it has significantly greater penetration into the cornea than the $\mathrm{CO} 2$ laser, as noted above. The laser spot diameter was $0.41 \mathrm{~mm}$ for treatment of rabbits, and $0.3 \mathrm{~mm}$ for treatment of eye bank eyes. A preliminary study in rabbits with cornea thickness of $0.385 \mathrm{~mm}$ (s.d., $0.016 \mathrm{~mm}$ ) showed that a treatment energy density of $10 \mathrm{~J} / \mathrm{cm}^{2}$ was the threshold at which endothelial necrosis was observed in acute experiments. At this energy density, altered stromal architecture and increased stain uptake was observed 4 weeks after treatment to a depth of $80 \%$ of the cornea thickness (Fig. 14).

The effect of laser treatment on eye bank eyes was assessed by photokeratoscope. The treatment energy was $9 \mathrm{~J} / \mathrm{cm}^{2}$, and the treatment pattern was 32 spots forming a circle of diameter 3 to $7 \mathrm{~mm}$, in $1 \mathrm{~mm}$ increments. Photokeratoscope measurements showed that the circle diameter had an inverse relation to the central steepening of the cornea, with the $3 \mathrm{~mm}$ circle causing about $22 \mathrm{D}$ of steepening and the $7 \mathrm{~mm}$ circle causing about $4 \mathrm{D}$ of steepening (Fig. 13).

The numerical analysis of the solid mechanics of the cornea performed by this group supported these experimental observations. They used the finite element method, which models a solid body as network of triangular elements and enforces the equations that govern the relation between internal forces and elongations or contractions in the body; it is a standard method of engineering analysis. It was assumed that a $40^{\circ} \mathrm{C}$ temperature increase was created to a depth of $75 \%$ of the cornea thickness, and that this caused a $12 \%$ shrinkage of collagen fibers in the cornea. For simplicity, the closely-spaced treatment spots were not modeled separately; instead, an annulus of shrunken tissue was created in the model. The model computed the response of nearby elastic tissue, using 


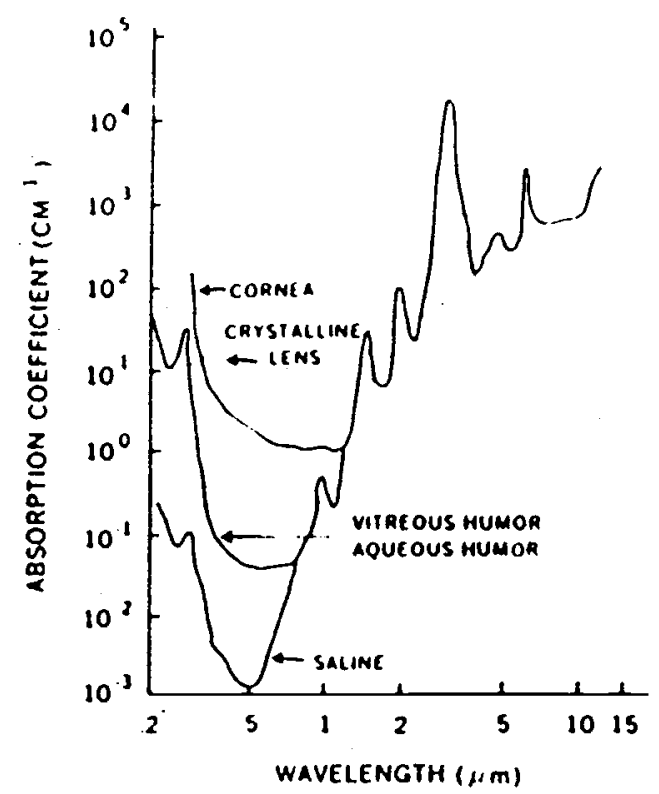

Ahsorption coctlicients of saline and ocular media of the primiate cyc Fig. 12 [Mihran, 1991][14]

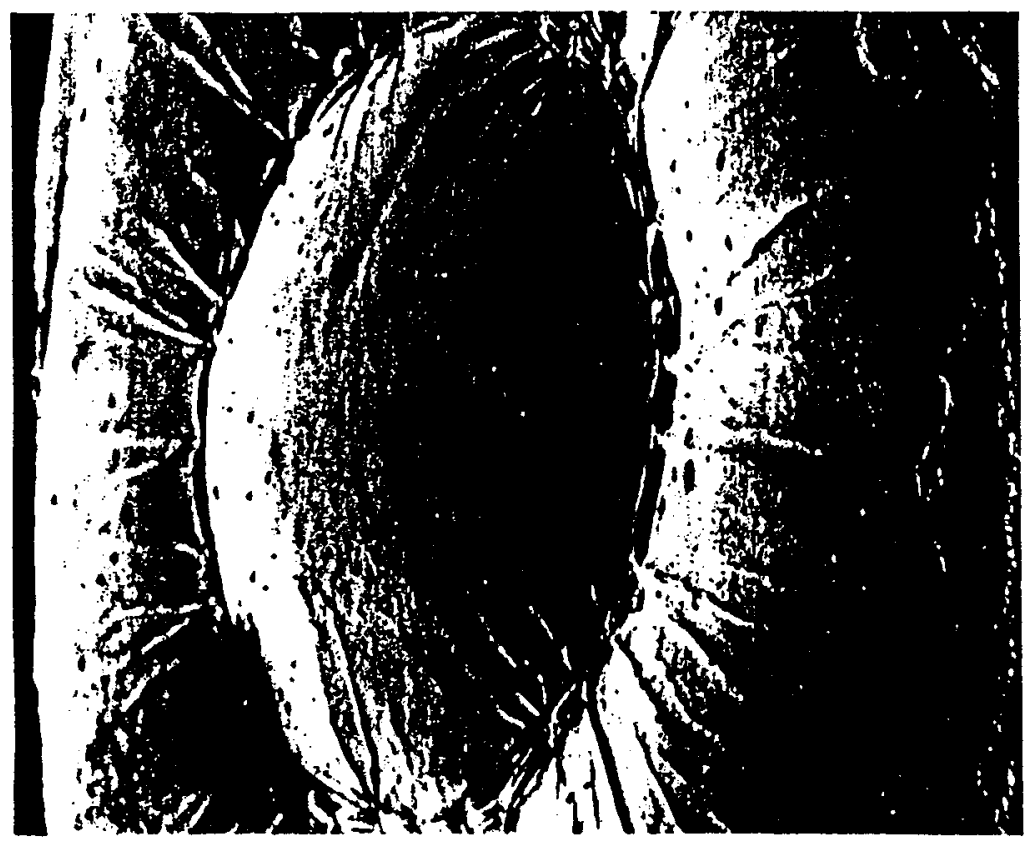

Scanning electron microscopy of a human eye bank cornea subjected to laser thermokeratoplasty. A belt-like effect is observed in the central comea. Fig. 13 [Moreira, et a1., 1993][20] 

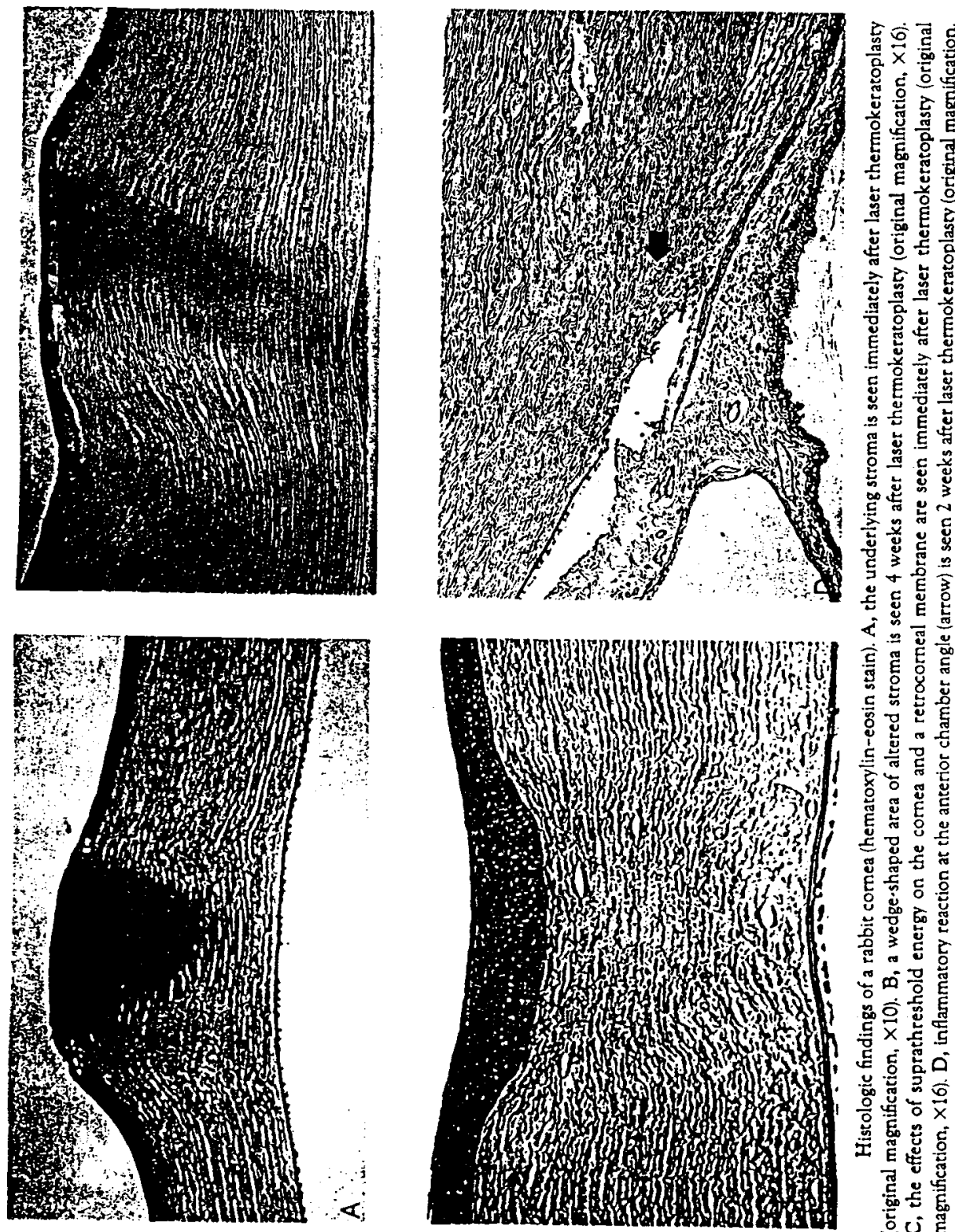

通至焉

氜

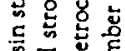

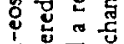

政

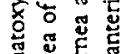

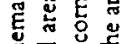

焉焉

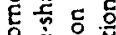

总

总总

的宁

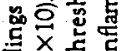

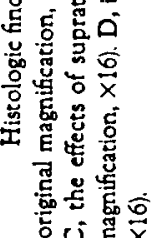

Fig. 14 [Moreira, et al., 1993] [20] 
appropriate mechanical properties of the cornea (Fig. 15). For a $3 \mathrm{~mm}$ treatment annulus, the model predicted about $22 \mathrm{D}$ of central steepening; for a $7 \mathrm{~mm}$ treatment annulus, the model predicted about $9 \mathrm{D}$ of central steepening, significantly more than the experimental value. Outside the treatment circle, flattening was predicted by the model, as was observed in their experiments. Note that the fraction of shrinkage they used was significantly smaller than the $57 \%$ values reported by Spörl $^{3}$.

Simon, et al. ${ }^{21}$ used the holmium:YAG laser to create treatment rings of diameter 3 to 7 $\mathrm{mm}$ with an energy density of $18 \mathrm{~J} / \mathrm{cm}^{2}$. In contrast to Moreira, et al.$^{20}$, they observed central flattening for treatment rings less than $3 \mathrm{~mm}$ in diameter, little effect for rings of 3 to $4 \mathrm{~mm}$ diameter, and central steepening for rings greater than $5 \mathrm{~mm}$ diameter. These results indicate a fundamental unresolved question in thermokeratoplasty, namely the direction and degree of central corneal curvature change in response to shrinkage enforced with circular patterns of various diameters.

\section{Laser Annular Thermokeratoplasty}

The laser heating technique of Chandonnet, et $a l .^{22}$ differs from others in creating a treated annulus on the cornea in a single heating, instead forming a circle from dots created in succession. Significantly, the effect of this treatment was to flatten the central cornea, not steepen it, as other laser heating methods did for the same diameter of treatment ring.

The energy source was a $\mathrm{CO} 2$ laser (wavelength $=10.6$ micron, absorption coefficient of $90 \mathrm{~mm}^{-1}$, penetration depth of $0.01 \mathrm{~mm}$ ). The beam passed through a spherical converging $\mathrm{ZnSe}$ lens (focal length of $30 \mathrm{~cm}$ ), then through a pair of complementary $\mathrm{ZnSe}$ axicons to create a fixed annular zone of heating with diameter of either $5.5 \mathrm{~mm}$ or $7.0 \mathrm{~mm}$; the thickness of the annulus was approximately $0.2 \mathrm{~mm}$ (Fig. 16). The laser was pulsed at $100 \mathrm{~Hz}$ with a pulse duration of $150 \mu \mathrm{sec}$. The average applied power was 1 watt, and total treatment duration varied between 30 and 90 seconds, giving total treatment energies of 30 to 90 joules.

Forty-two cadaver eyes were treated with this system. The transient temperature response was measured in the stroma and the anterior chamber with $0.125 \mathrm{~mm}$ diameter thermocouples. The stromal temperature attained $70^{\circ} \mathrm{C}$ for a treatment of about 90 seconds with 1 watt applied, and the anterior chamber temperature was approximately 20 ${ }^{\circ} \mathrm{C}$ lower. The curvature of the cornea was measured with a keratometer before and after treatment. The $5.5 \mathrm{~mm}$ diameter annulus produced flattening of about 12 diopters for treatments of 90 joules; shorter treatments produced a proportionally smaller flattening effect. The $7 \mathrm{~mm}$ annulus produced less than 2 diopters of flattening for any treatment energy.

Histological sections were taken and stained with hemotoxylin-phloxin-safran. The depth of thermal effect was about one-third the thickness of the cornea, or about 0.19 $\mathrm{mm}$. The width of the affected area was stated to be much greater than the $0.2 \mathrm{~mm}$ width of the annulus, but the value was not stated (Fig. 17). The authors believed that the flattening effect was due to the continuous, annular shape of the treatment zone, in contrast to the pattern of discrete dots used by other researchers to create central 


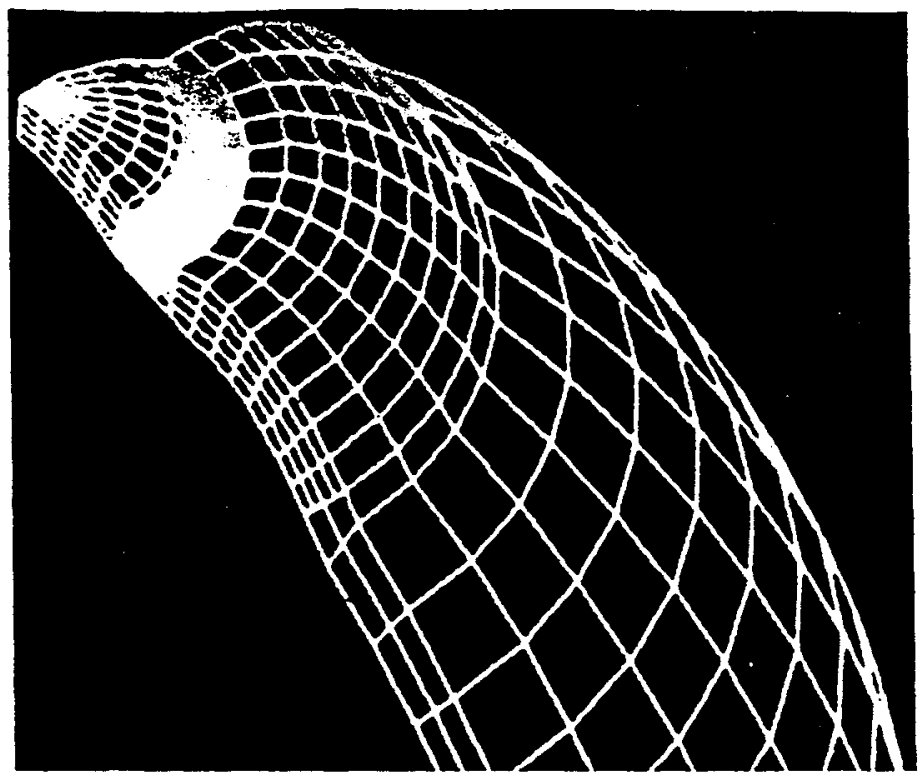

Finite element model of one quarter of the globe after application of circular pattern of heat to mid-peripheral cornea. Central cornea is steepened, and peripheral cornea is flattened. Corneal thinning is observed at sites of heat application.

Fig. 15 [Moreira, et a1., 1993][20]

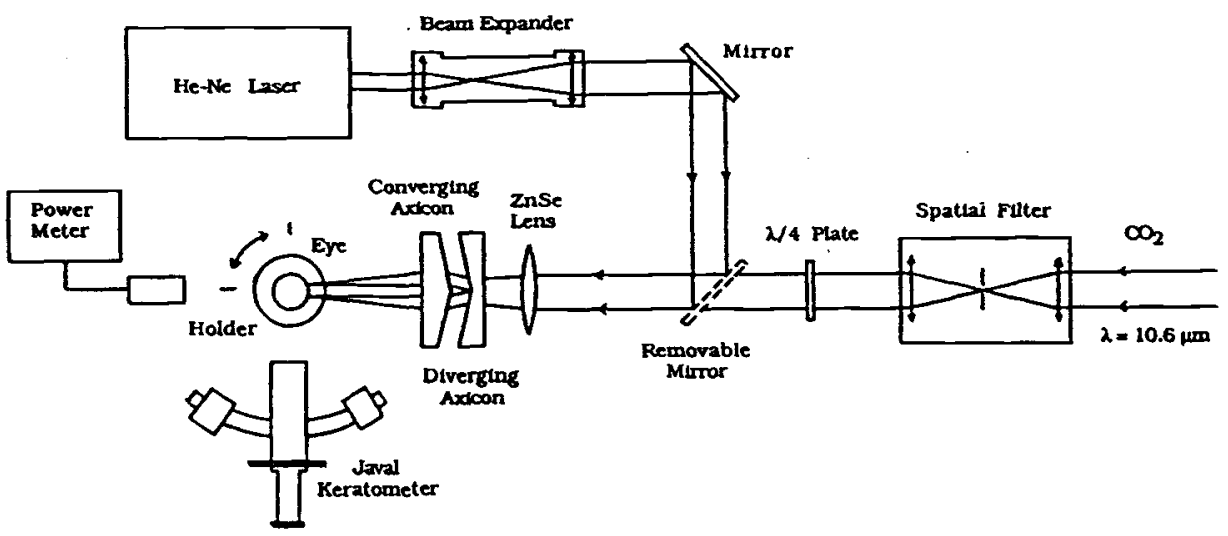

Schematic view of the experimental set-up. The eye holder was rotated $90^{\circ}$ before and after treatment to allow the keratometry reading.

Fig. 16 [Chandonnet, et a1., 1992][22] 


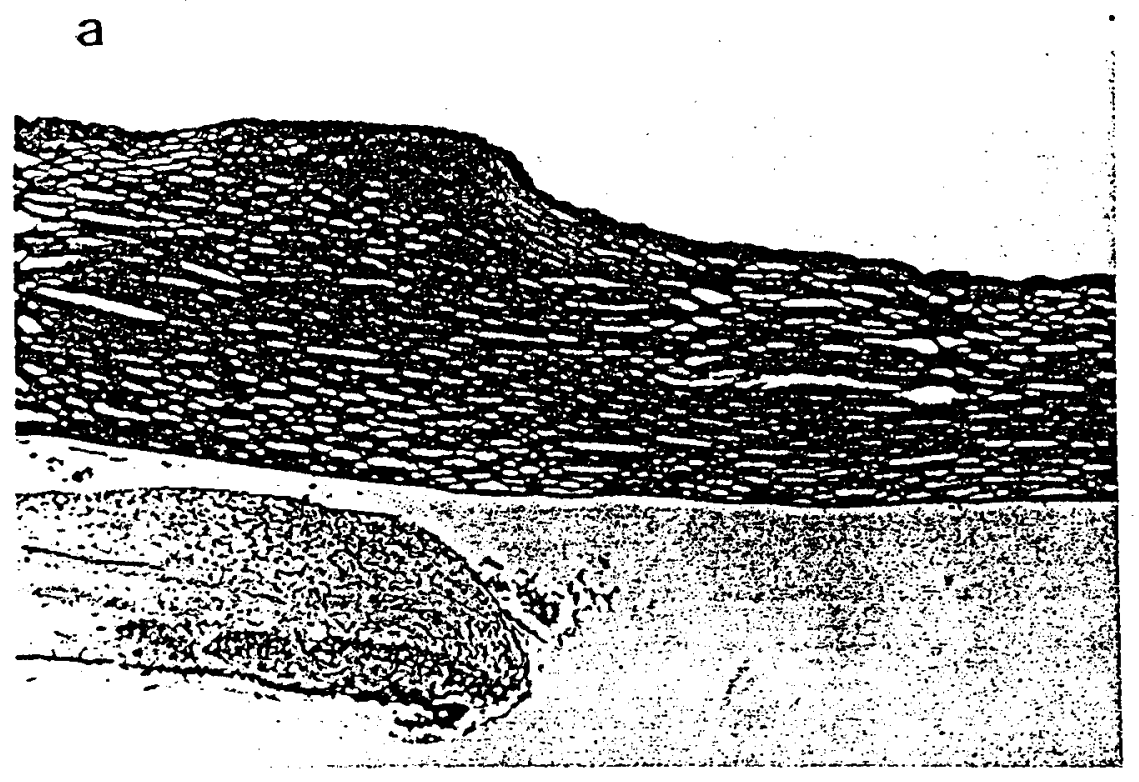

b

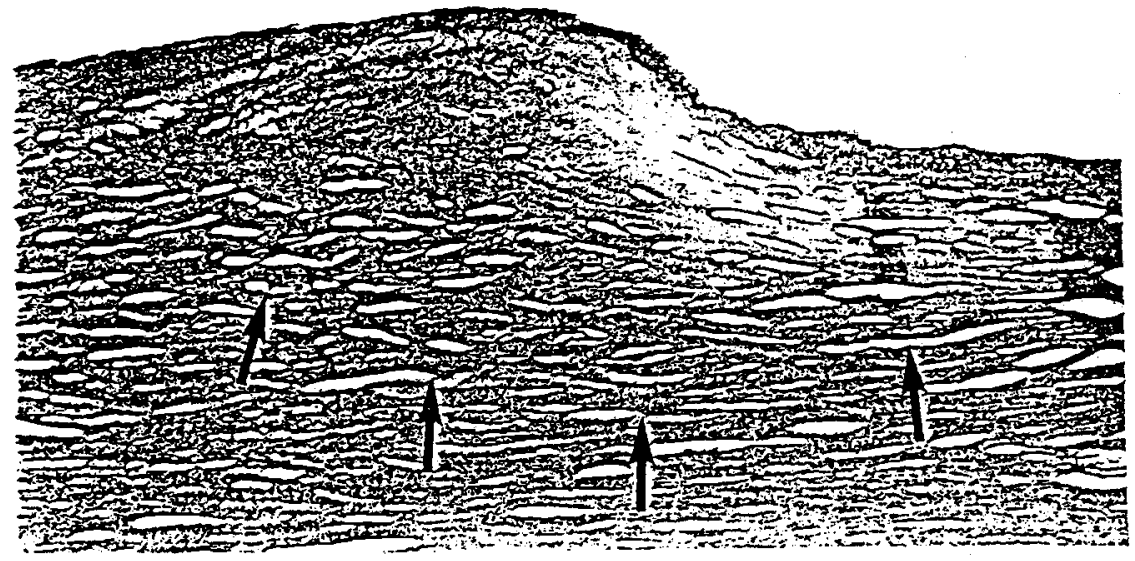

Histological sections. Hematoxylin-Phloxin-Safran staining. a: $(40 \times$ original magnification): Zones of collagen thermal damage is extending to the anterior one third of the corneal stroma (See arrows in b). b: $(400 \times$ original magnification): Higher magnification of the same area.

Fig. 17 [Chandonnet, et al., 1992][22] 
Matching the Energy Source to the Clinical Need / 69

steepening of the cornea. However, it must be noted that the finite element model of Moriera, et al. ${ }^{20}$ predicted central steepening in response to shrinkage of an annulus. It may be possible to reconcile these conflicting results by considering the long treatment times employed by Chandonnet, et $a^{22}$. With long treatment times, heat conduction toward the center of the cylindrical domain becomes significant, and elevated temperatures within the intended treatment ring result. In fact, in the steady state, the maximum temperature must occur at the center of the cornea. It is possible that shrinkage occurred at radius values within the treatment ring, and the effect on corneal curvature was that of the $3 \mathrm{~mm}$ treatment annulus that Simon, et al. ${ }^{21}$ observed to cause central flattening.

\section{Clinical Trials}

Ariyasu, et al..$^{23}$ treated 10 poorly-sighted eyes with the holmium:YAG laser and followed them for an average of 90 days. They observed no evidence of endothelial damage and achieved a mean increase in corneal curvature of $1.1 \mathrm{D}$. However, they observed varying amounts of regression.

Koch, et al. ${ }^{24}$ treated 17 hyperopic eyes with the holmium:YAG laser and followed 15 of them for two years. The treatment pattern was eight spots forming a circle of diameter 6 $\mathrm{mm}$. Pulse rate was $5 \mathrm{~Hz}$, pulse energy was $159 \mathrm{~mJ}$ to $199 \mathrm{~mJ}$, and pulse number was 10 , i.e., 10 pulses per spot. The mean refractive correction was $0.78 \mathrm{D}$ of steepening. The regression of effect between 14 days and two years was $0.2 \mathrm{D}$. They observed that "the amount of refractive correction at 2 years after surgery was correlated to the treatment pulse energy and the volume of the opacified tissue observed immediately after treatment."

Kohnen, et al ${ }^{25}$ treated 28 hyperopic eyes with the holmium:YAG laser and followed them for 18 months. The treatment pattern was: a) eight spots forming a circle of diameter $6 \mathrm{~mm}$, or b) two such circles, each of eight spots, with diameters of 6 and $7 \mathrm{~mm}$. Spot diameter was between 0.615 and $0.623 \mathrm{~mm}$, pulse rate was $5 \mathrm{~Hz}$, pulse energy was 208 to $242 \mathrm{~mJ}$, and pulse number was 10 . The mean refractive correction after eighteen months was $0.52 \mathrm{D}$ of steepening for the one-ring group and 1.41 D of steepening for the two-ring group. Stability after six months was described as good.

Vinciguerra, et al.$^{26}$ treated 16 hyperopic eyes with the holmium:YAG laser and followed them for one year. The treatment pattern was three rings, each of eight spots, forming circles of diameter 6,7 , and $8 \mathrm{~mm}$. In one group of patients, spots in successive circles were placed on radial lines; in a second group, the spots were staggered. Pulse energy was $30 \mathrm{~mJ}$, and pulse number was 7 . The mean refractive correction was $2.15 \mathrm{D}$ of steepening in the radial group and $1.50 \mathrm{D}$ of steepening in the staggered group. The treatments were described as "subject to a certain amount of regression."

Alio, et al. ${ }^{27}$ treated 57 hyperopic eyes with the holmium:YAG laser and followed them for 15 months. The treatment pattern was two or three rings with diameters of 6,7 , and 8 $\mathrm{mm}$, each consisting of eight spots. Spot diameter was between $0.6 \mathrm{~mm}$, pulse rate was 5 $\mathrm{Hz}$, pulse energy was $215 \mathrm{~mJ}$ to $255 \mathrm{~mJ}$, and pulse number was 10 . The mean keratometric power before treatment was $42.08 \mathrm{D}$ (s.d., $2.05 \mathrm{D}$ ) and $44.52 \mathrm{D}$ (s.d., 2.32 D) 15 months after treatment; this was statistically significant at $p<0.005$. Regression of 
effect was observed in visual acuity, in that $70.1 \%$ of eyes had visual acuity of $20 / 20$, but only $50.8 \%$ did at 15 months. Analysis of factors that may control regression indicated that this "regression of effect might be due to the elasticity of Bowman's membrane and stromal collagen in younger patients, or to thicker corneas, allowing the cornea to return to its original shape." They concluded that holmium:YAG laser thermokeratoplasty appears to be effective in correcting hyperopia up to $3 \mathrm{D}$ in those over 40 years of age with central corneas thinner than $0.525 \mathrm{~mm}$.

Nano and Muzzin ${ }^{28}$ treated 182 hyperopic eyes with the holmium:YAG laser and followed them for 1 year. Patient selection criteria included age 40 or older, cornea thinner than $0.55 \mathrm{~mm}$, and maximum $4 \mathrm{D}$ of hyperopia. Technical parameters were similar to those used by Alio, et al. ${ }^{27}$. After treatment, they observed moderate to severe haze at the treatment sites, which after 1 year became visible only under slit lamp examination. The slit lamp showed conical opacities in the treated corneas to a depth of 60 to $70 \%$. They also observed some regression of effect. At 1 month, $66 \%$ of eyes had uncorrected visual acuity of $20 / 30$ or better; at 12 months, $40 \%$ were $20 / 30$ or better.

\section{Tunable Diode Laser Thermokeratoplasty}

Brinkmann, et al.$^{17}$ have investigated a diode laser with a wavelength tunable between 1.845 and 1.871 microns by varying the diode temperature between $-10^{\circ} \mathrm{C}$ and $30^{\circ} \mathrm{C}$. In this range of wavelengths, the absorption coefficient in cornea varies rapidly (see Fig. 12), from $0.91 \mathrm{~mm}^{-1}$ to $2.04 \mathrm{~mm}^{-1}$, yielding variable penetration depths from $1.1 \mathrm{~mm}$ to $0.49 \mathrm{~mm}$. They heated the corneas of enucleated pig eyes with a fiber waveguide of diameter $0.3 \mathrm{~mm}$ placed in contact with the cornea and also in a non-contact mode, in which the beam was focussed at $0.7 \mathrm{~mm}$ in corneas of average thickness $0.857 \mathrm{~mm}$ (s.d., $0.059 \mathrm{~mm}$ ). The purpose of focussing was to increase local energy deposition at about $3 / 4$ depth in the cornea to compensate for energy absorbed by superficial layers. In this way, a more uniform axial temperature may be produced. At the depth of the endothelium, the beam is markedly defocussed so that thermal damage will not be produced there. The diode laser operates in a continuous wave mode, as opposed to a pulse mode, because the power output is low, about $500 \mathrm{~mW}$.

Typical treatment parameters were 8 spots created in a ring of diameter $6 \mathrm{~mm}$ using 200 $\mathrm{mW}$ power for a 10 second heating period for each spot. These parameters, as well as laser wavelength, were varied individually to study the effect on refractive changes in the eyes, and the contact and non-contact modes also were compared. Histological samples of the treated eyes were stained with serius-red stain and evaluated with polarized light microscopy.

The diameter of the treatment ring had an inversal effect on the refractive change: a $5 \mathrm{~mm}$ ring created $4 \mathrm{D}$ of steepening, while a $10 \mathrm{~mm}$ ring had almost no effect. The use of smaller penetrations depths caused surface ablation of tissue, producing a pit (Fig. 18). A saturation effect was observed when parameters such as heating time, heating power, or absorption rate were increased, in that further increases in the parameter created smaller refractive changes. The authors believe that over-heating of stromal tissue leads to homogenization of the collagen, i.e., disappearance of lamellae, in which state residual stresses cannot be maintained to produce a long-term refractive effect. Histological examination under polarized light supported this theory of varying zones of thermal 

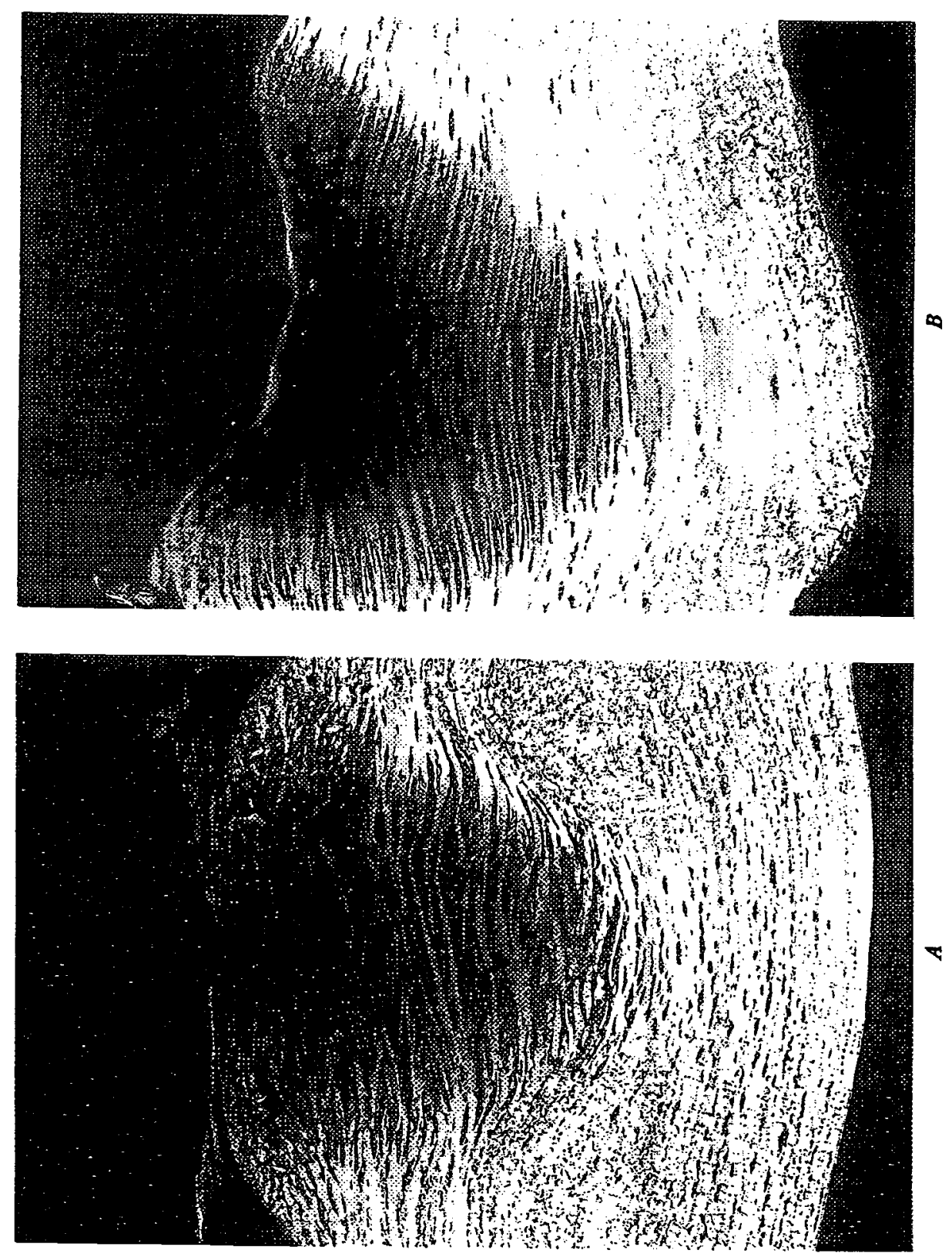

Fig. 18

[Brinkmann, et a1., 1998][17]
(Brinkmann) Histology of a coagulation under polarization light microscopy showing $2(A)$ and $3(B)$ zones of thermal damage. Application: contact mode-laser power $150 \mathrm{~mW}$; irradiation time 15 seconds A: Absorption $0.91 \mathrm{~mm}$ ': picture size $1.02 \times$ $1.53 \mathrm{~mm}$. B: Absorption $1.13 \mathrm{~mm}$ ': picture size $1.02 \times 1.53 \mathrm{~mm}$. C: Seclion of $A_{\text {; picture }}$ size $255 \times 382 \mu \mathrm{m}$. 
effect identified by the degree or absence of birefringence. This study illustrates possible advantages of the tunable diode laser in the clinic for heating to a controllable depth in corneas of varying thickness without creating the over-heated zones that may be associated with long-term regression of effect. The control of penetration depth may also permit protection of the endothelium in patients with corneas of varying thickness.

Geerling, et al.$^{29}$ treated 8 blind eyes with the tunable laser diode system. Wavelength was 1.854 micron (penetration depth, $1 \mathrm{~mm}$ ) or 1.870 micron (penetration depth, 0.5 $\mathrm{mm}$ ), treatment pattern was 1 or 2 rings of eight spots each, laser power was 100,130 , or $150 \mathrm{~mW}$ for 10 seconds, and inner diameter of the treatment ring was $5.0,5.5$, or $6.0 \mathrm{~mm}$. The patients were followed for 12 months. Central cornea steepening was observed immediately after treatment in response to coagulations that extended to 90 to $100 \%$ corneal depth. The mean change in refraction for the group treated with two rings was 2.32 D (s.d., $2.24 \mathrm{D}$ ). Most regression of effect occurred during the first 3 months, when the mean decreased from $3.93 \mathrm{D}$ (s.d., 2.22 D) to $2.95 \mathrm{D}$ (s.d., $2.01 \mathrm{D}$ ).

The group treated with the greater laser penetration depth showed greater endothelial defects under the coagulation site than the other group. At 3 months, these defects were not observed, "indicating that viable adjacent endothelial cells had spread and migrated to cover the area of cell damage." At 6 months, 2 patients measured showed no reduction in central endothelial cell count. Mid stromal coagulations could be seen at 12 months. The authors conclude that the 1.875 micron wavelength is safe and effective for clinical treatment. They plan to assess stability of refractive effect in a study in sighted eyes.

It would appear to be an advantage to simplify laser thermokeratoplasty treatments by delivering laser energy in an annular pattern, instead of with multiple spots. This would eliminate error associated with variable placement of the spots and variable power delivered to each spot. Given that the closely-spaced spots are intended to form a ring, delivering a ring of laser energy would seem the most repeatable technique. Chandonnet et $a .^{22}$ demonstrated this technique with the $\mathrm{CO} 2$ laser, but it does not appear to have been used with the holmium:YAG laser or diode lasers.

Finally, it must be noted that in spite of partial success in treatment of hyperopic patients, the mechanics of collagen shrinkage and curvature change of the cornea are not fully understood. The finite element model of Moreira, et al..$^{20}$ predicted steepening of the central cornea in response to a treatment ring of diameter $3 \mathrm{~mm}$; treatments of eye bank eyes corroborated this. However, Chandonnet et al. ${ }^{22}$ observed central flattening of the cornea in response to $\mathrm{CO} 2$ laser thermokeratoplasty with a treatment ring of diameter 5.5 to $7.0 \mathrm{~mm}$. Simon, et al. ${ }^{21}$ observed central corneal flattening for rings of less than $3 \mathrm{~mm}$ diameter and central corneal steepening for rings of greater than $5 \mathrm{~mm}$ diameter delivered with the holmium:YAG laser. These observations are not all directly comparable, because the $\mathrm{CO} 2$ laser deposits energy only very near the surface of the cornea; nonetheless, the contradictions inherent in these differing results must be resolved in order to design safe and effective thermokeratoplasty treatment systems.

\section{Microwave Thermokeratoplasty}

Microwave thermokeratoplasty (MTK) uses microwave energy emitted from a near-field applicator to shrink stromal collagen and modify the dioptric power of the cornea ${ }^{30}$. 
Electric field lines form a fringing pattern that extends into the cornea to a depth controlled by the applicator geometry. The electric field causes the polar water molecules to align themselves with the field; the rapid reversal of the sinusoidallyvarying field causes frictional heating by these molecules as they rotate in place. This effect does not require a conduction current to flow through a point of electrical contact between a conductor and tissue; heating takes place even if an electrical insulator is interposed, as is the case in a microwave oven. In this way, the method is distinct from radio-frequency heating, which requires electrical contact. A typical frequency of operation for microwave heating of tissue is around $1000 \mathrm{MHz}$, while radio frequency systems operate at around $1 \mathrm{MHz}$. In electromagnetic terms, the microwave system uses a displacement current, and the radio frequency system uses a conduction current. The exact microwave frequency value is dictated by the FCC, which permits the use of 915 $\mathrm{MHz}$ or $2450 \mathrm{MHz}$ for industrial, scientific, and medical uses (ISM frequencies).

The MTK applicator is depicted in Fig. 19. It is curved to fit approximately flush on the cornea. The MTK applicator was designed to deposit microwave energy in an annular pattern of $3.5 \mathrm{~mm}$ diameter to depths in the cornea of a fraction of a millimeter. The probe consists of two concentric, conducting tubes separated by an insulator (coaxial cable) that are connected to a coaxial feedline from a microwave generator. The applicator deposits power $\left(\mathrm{W} / \mathrm{m}^{3}\right)$ in the cornea with the pattern shown in Fig. 20, which shows an early, flat version of the applicator. This pattern was computed by the finite difference time domain (FDTD) method (MAFIA, Darmstadt, Germany). The depth of penetration is controlled chiefly by the spacing between conductors, the thickness of the insulating layer, and the width of the gap for coolant flow; these factors are fixed at the time of construction. Unlike the case of a theoretical plane wave propagating in a lossy medium, the depth of penetration here is not determined by the driving frequency. At $915 \mathrm{MHz}$, the penetration depth for power in a plane wave would be about $12 \mathrm{~mm}$ in tissue, but for the MTK applicator this depth is about $0.5 \mathrm{~mm}$.

The applicator incorporates a cooling system to prevent significant temperature elevation in the epithelium, while heating the mid-stroma, as did the radio-frequency CSE probe developed by Doss and Albilar ${ }^{11}$. The MTK cooling system is closed to eliminate the need to form a water-tight seal on the peripheral cornea with the outer edges of the applicator. The coolant flows at $20 \mathrm{ml} / \mathrm{min}$, and this produces an effective heat transfer coefficient through the applicator tip of about $1000 \mathrm{~W} /\left(\mathrm{m}^{\circ} \mathrm{C}\right)$, accounting for both conduction through the tip and forced convection on the inside surface of the tip. The transient heat transfer response in the cornea was computed approximately by assigning to the cornea the thermal conductivity, specific heat, and mass density of water, incorporating the microwave power deposition pattern in Fig. 20 as an input, and treating the heat transfer coefficient and coolant temperature (equal to $35^{\circ} \mathrm{C}$ ) as a mixed boundary condition. The heat transfer equation was solved by the finite element method using the MATLAB PDE Solver. These results indicated the role of heating duration in treatment planning. Specifically, as heating duration increased from 1 to 2 to 4 seconds, the temperature in the central cornea and the endothelium became significantly elevated (Fig. 21). In the steady-state, the maximum temperature would be found at the center of the cornea, because the heating pattern is an annulus surrounding the center; this is undesirable, because no shrinkage of collagen in the optical zone is desired.

Consequently, heating durations of 1 or 2 seconds have been used with adjustment of power level so that $60^{\circ} \mathrm{C}$ is attained at mid-stroma. The heat transfer analysis also demonstrated the disadvantage of using room temperature coolant on a cornea at body 
74 / Critical Reviews Vol. CR75
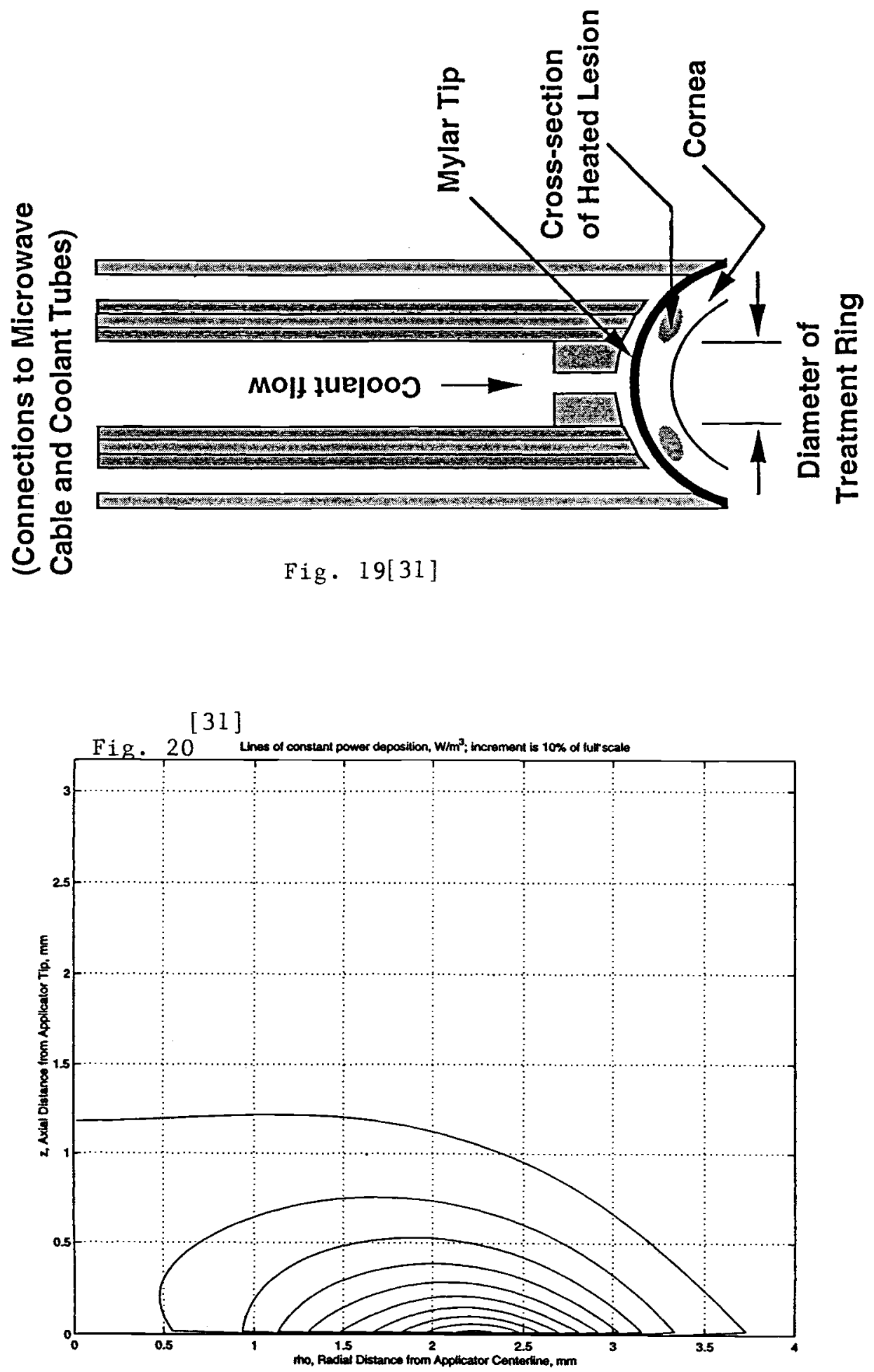

Proc. of SPIE Vol. 10297 1029704-24 
Matching the Energy Source to the Clinical Need / 75

temperature: the location of the maximum temperature then is displaced deeper toward the endothelium. This effect was avoided in practice by using a coolant of the same temperature as the tissue.

\section{MTK in ex vivo Tissue}

The MTK applicator was used to heat the corneas of enucleated pig eyes to demonstrate feasibility of the technique as a treatment for myopia ${ }^{31}$. Fourteen enucleated porcine globes were heated with the applicator described above. Treatment parameters were: 33 to 35 watts of forward microwave power, $20 \mathrm{ml} / \mathrm{min}$ of coolant flow rate, 19 to $21^{\circ} \mathrm{C}$ coolant temperature, and a 2 second heating duration. Actual power absorbed in tissue was much less than the forward power, due to reflected power and losses in the applicator.

The curvature of each cornea was measured before and after treatment with a Keratron videokeratoscope, using the $3 \mathrm{~mm}$ Simulated $\mathrm{K}$ reading at the center of the treatment ring. A slit lamp exam was performed, and the cornea thickness was measured with a Sonomed Model 200P pachymeter. Selected eyes were sectioned across the diameter of the treatment ring and stained with hematoxylin-eosin for histological evaluation. The mean thickness of 6 corneas was $0.93 \mathrm{~mm}$ (s.d., $0.03 \mathrm{~mm}$ ) pre-treatment; after treatment, mean thickness was $0.906 \mathrm{~mm}$ (s.d., $0.035 \mathrm{~mm})(\mathrm{N}=6)$.

The treatment ring was identifiable by stromal opacity visible beneath an intact epithelium. The mean inner diameter of the treatment ring was $3.2 \mathrm{~mm}$ (s.d., $0.3 \mathrm{~mm}$ ) $(\mathrm{N}=14)$. The mean ring thickness was $0.63 \mathrm{~mm}$ (s.d., $0.2 \mathrm{~mm}$ ). The mean depth of opacity observed in the slit lamp exam was $62 \%$ (s.d., $26 \%$ ) of cornea thickness. Slit lamp examination showed that the epithelium was intact in all eyes $(\mathrm{N}=14)$. The mean $\mathrm{K}$ value for corneas pre-treatment was $37.1 \mathrm{D}$ (s.d., 1.5 D) $(\mathrm{N}=14)$; the mean $\mathrm{K}$ value posttreatment was $29.3 \mathrm{D}$ (s.d., 5.5 D). This gives an average refractive correction of $-7.7 \mathrm{D}$ (s.d., 6.3 D), i.e., flattening of the central cornea; half of the corneas had between 5 and $15 \mathrm{D}$ of flattening.

Histological examination showed a dark region of stain uptake at the location of the heated ring. The region of stain uptake corresponded to the depth of opacity observed in the slit lamp exam, and did not extend to the epithelium, which was intact in all cases. The cornea surface bulged upward above the site of stain uptake. The endothelium was morphologically normal (Fig. 22).

There was significant variation in refractive outcome in this evaluation of MTK. This is believed to be due to varying pressure on the cornea as the applicator is applied; future applicators will control this variable.

The penetration depth of the MTK applicator is comparable to the penetration depth of laser energy used by diode and holmium:YAG laser thermokeratoplasty systems, and this depth is controllable through the geometry of the applicator. This fact will be exploited in the development of an applicator for use in the clinic. The mean depth of opacity observed was $62 \%$ of corneal thickness, in pig corneas with a mean thickness of 0.93 $\mathrm{mm}$. In a human cornea of thickness $0.55 \mathrm{~mm}$, the depth of opacity would be greater than 
76 / Critical Reviews Vol. CR75
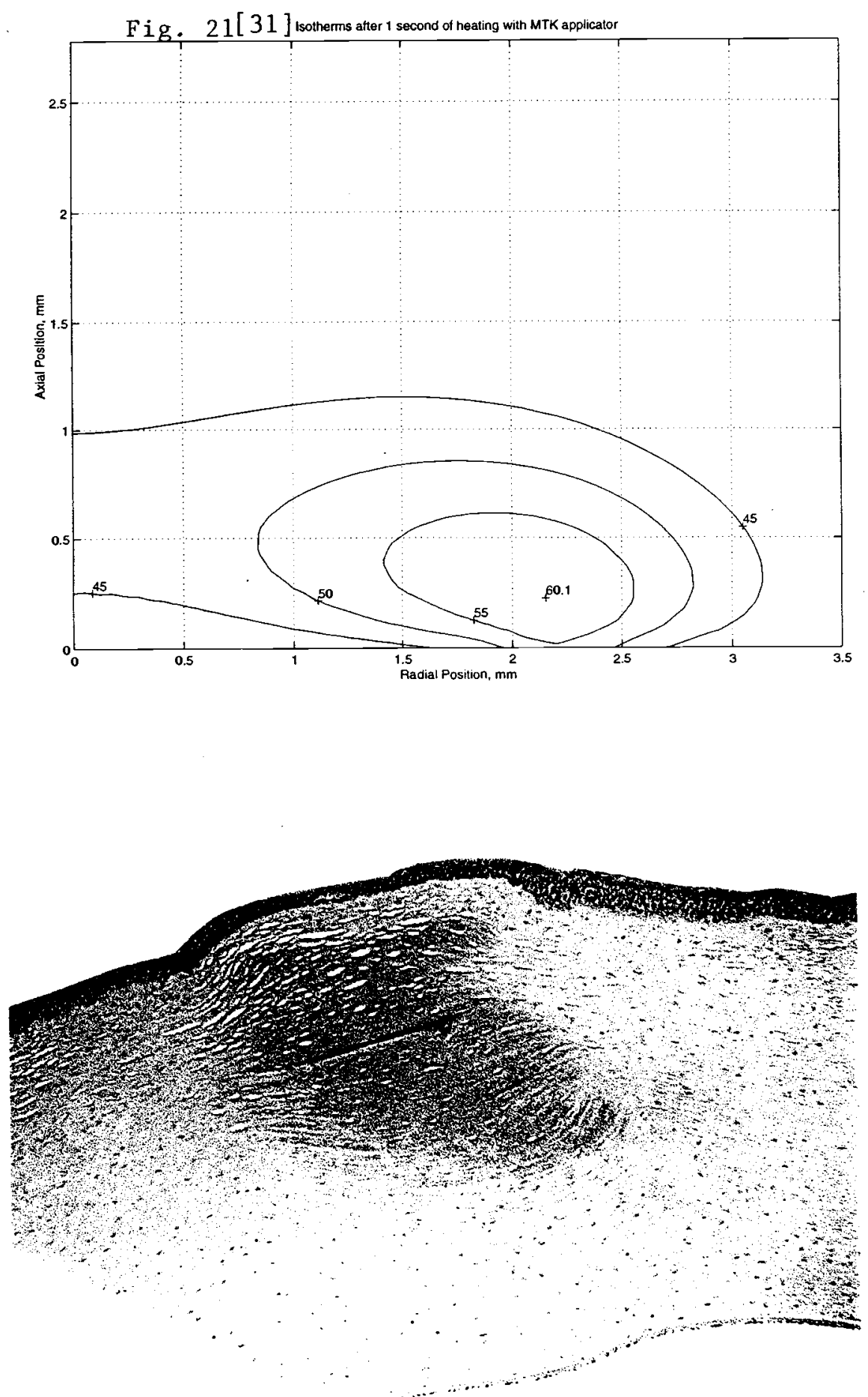

Fig. 22 Photo micrograph of pig cornea heating by MTK system (hematoxylineosin stain)[31] 
full depth, and endothelial damage could result. The authors plan to reduce the penetration depth of the MTK applicator to reduce this possibility in the clinic.

The central flattening effect of MTK is the opposite of the central steepening effect reported after laser thermokeratoplasty treatments that used six or eight dots in a circle of diameter $5 \mathrm{~mm}$ or greater. The cause of this difference is not clear, but treatment ring diameter seems to be a factor. The $3.5 \mathrm{~mm}$ diameter treatment ring used in the MTK study has been observed to flatten the central cornea in one laser thermokeratoplasty study ${ }^{21}$. Against this must be considered the findings of Moreira, et al ${ }^{20}$, whose experimental observations and numerical modeling of the solid mechanics of the cornea showed central steepening in response to shrinkage in an annulus of diameter down to 3 $\mathrm{mm}$. An improved understanding of collagen shrinkage and the biomechanics of the cornea is necessary before optimal treatments can be designed.

The MTK technique does not intervene in the optical zone, requires no surgical incisions, has controllable depth of penetration, heats in a single one-second procedure, and uses less expensive equipment than laser systems. Furthermore, it spares the epithelium, allowing videokeratometry to be performed on a normal epithelium immediately after treatment and eliminates the healing period required for regrowth. The authors will continue to develop this technique to improve repeatability and compare its performance to existing methods for refractive surgery.

\section{Conclusion}

Thermokeratoplasty may prove to be a safe and effective method for refractive surgery. In order to maximize the potential of this method, the shrinkage phenomenon of stromal collagen and the biomechanics of the cornea must be better understood.

\section{ACKNOWLEDGEMENTS}

The microwave thermokeratoplasty research described in this paper was supported by NIH grant 1R41 EY11185.

The author would like to acknowledge the kind permission of the researchers who permitted reproduction of figures from their own publications in this article.

\section{REFERENCES}

1. Ren, Q. S., R.H. Keates, R.A. Hill, M.W. Berns, "Laser refractive surgery - A review and current status." Optical Engineering 34(3): 642-660, 1995.

2. Stringer, H., J. Parr, "Shrinkage temperature of eye collagen." Nature 204: 1307, 1964.

3. Spörl, E., U. Genth, K. Schmalfuss, T. Seiler, "Thermo-mechanisches Verhalten der Hornhout." Klin Monatsbl Augenheilkd 208: 112-116, 1996. 
4. Lans, L. J., "Experimentelle untersuchungen uber entshehung von astigmatismus durch nicht-perforirende corneawunden." Albrecht von Graefes Arch. Klin. Exp. Ophthalmol. 45: 117-152, 1898.

5. Gasset, A. R., H.E. Kaufman, "Thermokeratoplasty in the treatment of keratokonus." American Journal of Ophthalmology 79(2): 1975, 1975.

6. Shaw, E. L., A.R. Gasset, "Thermokeratoplasty (TKP) temperature profile." Investigative Ophthalmology 13(3): 181-186, 1974.

7. Keates, R. H., J. Dingle, "Thermokeratoplasty for keratoconus." Ophthalmic Surgery 6(3): 89-92, 1975.

8. Neumann, A. C., D.R. Sanders, J.J. Salz, D.J. Bessinger, M.G. Raanan, M. Karr, "Effect of thermokeratoplasty on corneal curvature." J Cataract Refract Surg 16(November): 727-731, 1990.

9. Feldman, S. T., W. Ellis, J. Fruct-Pery, A. Chayet, S.I. Brown, "Experimental radial thermokeratoplasty in rabbits." Arch Ophthalmol 108: 997-1000, 1990.

10. Neumann, A. C., D. Sanders, M. Raanan, M. DeLuca, "Hyperopic thermokeratoplasty: Clinical evaluation." J Cataract Refract Surg 17(November): 830-838, 1991 .

11. Doss, J. D., J.I. Albillar, “A technique for the selective heating of corneal stroma." Contact Lens Jan/March: 13-17, 1980.

12. Rowsey, J. J., J.D. Doss, "Preliminary report of Los Alamos keratoplasty techniques." Ophthalmology 88: 755-760, 1981.

13. Rowsey, J. J., "Electrosurgical keratoplasty: update and retraction." Invest. Ophthalmol. Vis. Sci. 28(suppl): 224, 1987.

14. Mihran, R., "Interaction of laser radiation with structures of the eye." IEEE Transactions on Education 34(3): 250-259, 1991.

15. Peyman, G. A., B. Larson, M. Raichand, A.H. Andrews, "Modification of rabbit corneal curvature with use of carbon-dioxide laser burns." Ophthalmic Surgery and Lasers 11(5): 325-329, 1980.

16. Beckman, H., T.A. Fuller, R. Boyman, et al., "Carbon dioxide laser surgery of the eye and adnexa." Ophthalmology 87: 990-1000, 1980.

17. Brinkmann, R., N. Koop, G. Geerling, J. Kampmeier, S. Borcherding, K. Kamm, R. Birngruber, "Diode laser thermokeratoplasty: Application strategy and dosimetry." Journal of Cataract and Refractive Surgery 24(9): 1195-1207, 1998.

18. Seiler, T., M. Matallana, T. Bende, "Laser thermokeratoplasty by means of a pulsed holmium:YAG laser for hyperopic correction." Refract Corneal Surg 6: 325-329, 1990.

19. Horn, G., K.G. Spears, O. Lopez, A. Lewicky, X.Y. Yang, M. Riaz, R.Y. Wang, D. Silva, J. Serafin, "New refractive method for laser thermal keratoplasty with the CoMGF2 laser." Journal of Cataract and Refractive Surgery 16(5): 61 1-616, 1990.

20. Moreira, H., M. Campos, M.R. Sawusch, J.M. McDonnell, B. Sand, P.J. McDonnell, "Holmium laser thermokeratoplasty." Ophthalmology 100(5): 752-761, 1993.

21. Simon, G., Q.S. Ren, J.-M. Parel, "Non-contact laser photothermal keratoplasty (LPTK): II Refractive effects, treatment parameters, and therapeutic applications." $J$. Refract. Corneal Surg. 10: 519-528, 1994.

22. Chandonnet, A., R. Bazin, C. Sirois, P.A. Belanger, "CO2 laser annular thermokeratoplasty." Lasers in Surgery and Medicine 12: 264-273, 1992.

23. Ariyasu, R. G., B. Sand, R. Menefee, D. Hennings, C. Rose, M. Berry, J.J. Garbus, P.J. McDonnell, "Holmium laser thermal keratoplasty of 10 poorly sighted eyes." Journal of Refractive Surgery 11(5): 358-365, 1995.

24. Koch, D. D., A. Abarca, R. Villarreal, R. Menefee, T. Kohnen, A. Vassiliadis, M. 
Berry, "Hyperopia correction by noncontact holmium: YAG laser thermal keratoplasty- clinical study with a two-year follow-up." Ophthalmology 103(5): 731 $740,1996$.

25. Kohnen, T., D.D. Koch, P.J. McDonnell, R.F. Menefee, M.J. Berry, "Noncontact holmium: YAG laser thermal keratoplasty to correct hyperopia: 18-month followup." Ophthalmologica 211(5): 274-282, 1997.

26. Vinciguerra, P., T. Kohnen, M. Azzolini, P. Radice, D. Epstein, D.D. Koch, "Radial and staggered treatment patterns to correct hyperopia using noncontact holmium:YAG laser thermal keratoplasty." Journal of Cataract and Refractive Surgery 24(1): 21-30, 1998.

27. Alio, J. L., M.M. Ismail, J.L.S. Pego, "Correction of hyperopia with noncontact Ho: YAG laser thermal keratoplasty." Journal of Refractive Surgery 13(1): 17-22, 1997.

28. Nano, H. D., S. Muzzin, "Noncontact holmium: YAG laser thermal keratoplasty for hyperopia." Journal of Cataract and Refractive Surgery 24(6): 751-757, 1998.

29. Geerling, G., N. Koop, R. Brinkmann, A. Tungler, C. Wirbelauer, R. Birngruber, "Continuous-wave diode laser thermokeratoplasty: First clinical experience in blind human eyes." Journal of Cataract and Refractive Surgery 25(1): 32-40, 1999.

30. Trembly, S., R. Keates, "Combined microwave heating and surface cooling of the cornea." IEEE Trans. Biomed. Engr. 38(1): 85-91, 1991.

31. Roberts, J., S. Trembly, N. Hashizume, K.L. Moodie, N.K. Tripoli, K.L. Cohen, P.J. Hoopes, "Microwave thermokeratoplasty: Keratoscopic evaluation in enucleated porcine eyes." ARVO Conference Proceedings(May), 1999.

32. Laservue (1999). Commercial brochure. Montreal, Quebec, Rene Laennee Medical Center.

33. Davson, H. (1980). Physiology of the Eye. New York, Academic Press.

34. Dorland, W. A. N. (1980). Illustrated Medical Dictionary. Philadelphia, W.B. Saunders.

35. Aquavella, J. V., "Thermokeratoplasty." Ophthalmic Surgery 5: 39-47, 1974.

36. Pang, D., "Microwave thermokeratoplasy for reshaping corneal contour." M.S. Thesis, Dartmouth College, May, 1994. 